\title{
Assessment of physical activity and energy expenditure: an overview of objective measures
}

\author{
Andrew P. Hills ${ }^{1,2}$, Najat Mokhtar ${ }^{3}$ and Nuala M. Byrne ${ }^{4}$ \\ ${ }^{1}$ Centre for Nutrition and Exercise, Mater Research Institute, University of Queensland, South Brisbane, QLD, Australia \\ ${ }^{2}$ Griffith Health Institute, Griffith University, Gold Coast, QLD, Australia \\ ${ }^{3}$ Nutritional and Health-Related Environmental Studies Section, International Atomic Energy Agency, Vienna, Austria \\ ${ }^{4}$ Faculty of Health Sciences and Medicine, Bond University, Gold Coast, QLD, Australia
}

\section{Edited by:}

Tim R. Nagy, University of Alabama at Birmingham, USA

Reviewed by:

Amanda Willig, University of Alabama at Birmingham, USA

David A. Fields, University of Oklahoma Health Sciences Center, USA

\section{*Correspondence:}

Andrew P. Hills, Centre for Nutrition and Exercise, Mater Research Institute, University of Queensland, Aubigny Place, Raymond Terrace,

South Brisbane, QLD 4101, Australia e-mail: ahills@mmri.mater.org.au
The ability to assess energy expenditure (EE) and estimate physical activity (PA) in free-living individuals is extremely important in the global context of non-communicable diseases including malnutrition, overnutrition (obesity), and diabetes. It is also important to appreciate that PA and EE are different constructs with PA defined as any bodily movement that results in EE and accordingly, energy is expended as a result of PA. However, total energy expenditure, best assessed using the criterion doubly labeled water (DLW) technique, includes components in addition to physical activity energy expenditure, namely resting energy expenditure and the thermic effect of food. Given the large number of assessment techniques currently used to estimate PA in humans, it is imperative to understand the relative merits of each. The goal of this review is to provide information on the utility and limitations of a range of objective measures of PA and their relationship with EE. The measures discussed include those based on EE or oxygen uptake including DLW, activity energy expenditure, physical activity level, and metabolic equivalent; those based on heart rate monitoring and motion sensors; and because of their widespread use, selected subjective measures.

Keywords: physical activity assessment, human energy expenditure, objective measurement techniques, stable isotopes, accelerometry

\section{INTRODUCTION}

Physical activity measurement approaches are commonly used to quantify the amount and type of movement undertaken by individuals in different settings. In many cases, objective physical activity (PA) measurement approaches are also used to predict energy expenditure (EE). The ability to estimate PA and assess EE in free-living individuals is extremely important in the global context of increasing rates of obesity and type 2 diabetes mellitus and other non-communicable diseases (NCDs).

It is important to appreciate that PA and EE are different constructs. PA is defined as any bodily movement that results in EE (1) and accordingly, energy is expended as a result of PA. Simply stated, PA is a behavior that results in an elevation of $\mathrm{EE}$ above resting levels. The terms are often considered synonymous but are inherently different and can be assessed using different approaches (2). The criterion or "gold standard" approach to assess total energy expenditure (TEE) in a free-living context is the doubly labeled water (DLW) technique. TEE is comprised of multiple components including physical activity energy expenditure (PAEE), resting energy expenditure (REE), and the thermic effect of food (TEF). Despite PA being a complex and multifaceted construct measured using many approaches, unlike for the measurement of TEE, there is no recognized "gold standard" technique $(3,4)$.

A large number of objective measurement approaches are available to quantify PA and EE of different populations. However, the accurate measurement of EE and PA in many groups, including children, is very challenging $(5,6)$ due to their intermittent and often sporadic movement (7). Because PA is a complex and multidimensional behavior, precise quantification can be difficult (8). A major challenge in PA and nutritional epidemiology is the choice of the most accurate and objective measure suitable for large populations $(8,9)$. The choice of assessment approach for both PA and $\mathrm{EE}$ is influenced by numerous factors including affordability and participant burden (10). Additional factors include the age of participants, sample size, assessment time frame, the type of PA information required, data management options, and measurement error associated with the approach (11-14). Fundamentally, all measurement techniques have inherent strengths and limitations, and there is often value in using combined approaches. Some of the important considerations include the following:

- How was the technique derived - was it based on EE, heart rate (HR), or accelerometry data?

- What is the cost of the technique and how practical or convenient is it for participants and investigators?

- What is the intended use, for example to assess the impact of PA on energy balance, metabolic health or a component of fitness, and in a small or large-scale study?

The goal of this review is to provide information on the utility and limitations of a range of objective measures of PA and their 


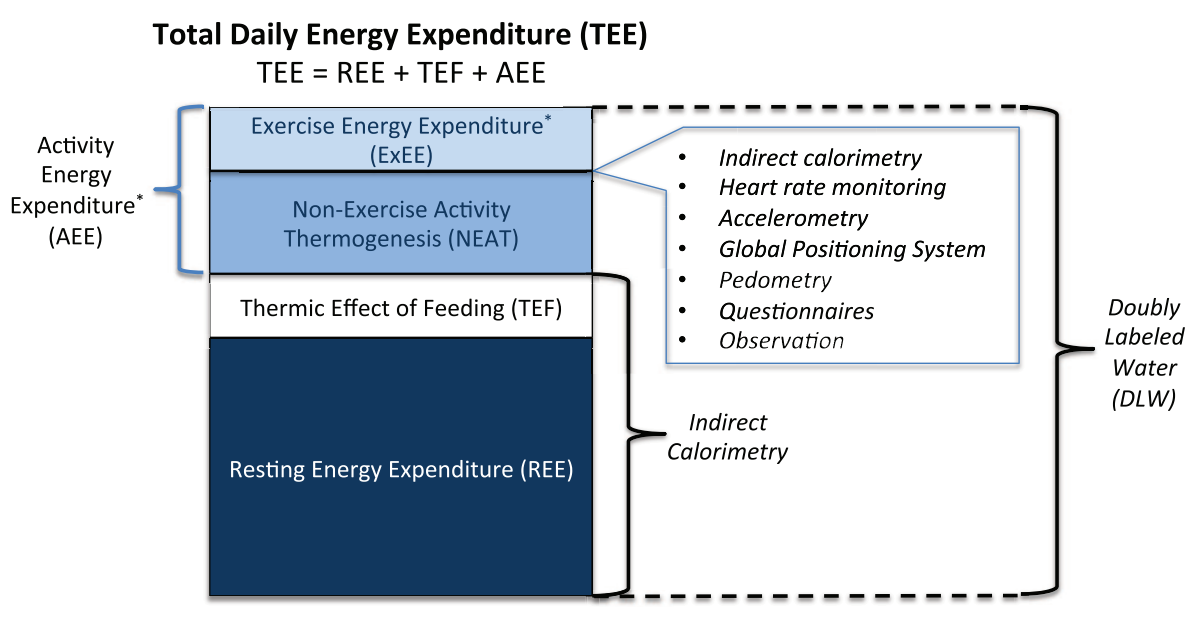

* EXEE and thus AEE are the most variable components of TEE. Therefore, the proportions of TEE and of REE, TEF and AEE differ between individuals.

FIGURE 1 | Components of total daily energy expenditure and measurement approaches.

relationship with EE. Definitions of major terminology are followed by an overview of selected objective approaches to assess PA and EE. Measures discussed include those based on EE or oxygen uptake including DLW, activity energy expenditure (AEE), physical activity level (PAL), and metabolic equivalent (MET); those based on HR monitoring and motion sensors (pedometers and accelerometers); and because of their widespread use, subjective measures including selected physical activity questionnaires (PAQs).

\section{TERMINOLOGY}

Inconsistent use of terminology has impacted the fields of nutrition, PA, exercise, and EE assessment, therefore, an overview of key terminology is a useful starting point. PA is a global term traditionally defined as bodily movement resulting from contraction of skeletal muscle that results in an increase in $\mathrm{EE}$ above resting levels (1). In turn, PA can be categorized on the basis of context or setting to include leisure-time or recreational PA and subcomponents of sport, transportation, and occupational activity. Alternatively, exercise is commonly defined as planned, structured, and repetitive movement with the intention of promoting or maintaining one or more components of physical fitness (1). PA and exercise can be quantified according to intensity (how hard?), duration (how long?), frequency (how often?), and mode (or type), such as walking, running, swimming, etc. (15). Howley (16) provides a useful overview of the various terms associated with PA and exercise plus guidelines for consistent interpretation of exercise intensity and volume.

As mentioned above, an outcome of participation in PA or exercise is the expenditure of energy, commonly quantified in terms of intensity. Intensity can be referenced in different ways (16). For example, intensity of aerobic exercise is typically referenced using increase in HR in beats per minute or the energy expended over and above the body's resting requirements to quantify PA as AEE or as exercise energy expenditure (ExEE). Similarly, AEE and ExEE can be expressed relative to resting values where $1 \mathrm{MET}$ at rest equates to $3.5 \mathrm{~mL} / \mathrm{O}_{2} / \mathrm{kg} / \mathrm{min}^{-1}$ or $1 \mathrm{kcal} / \mathrm{kg} / \mathrm{h}$. It is important to note that the conversion of MET to kilocalories can be erroneous when using these standard conversion factors (17-20). However, the use of a correction factor based on measured or predicted resting metabolic rate (RMR) can reduce this error in some activities (18). Further detail regarding the MET concept is provided in a later section.

Gross EE is quantified on the basis of oxygen consumption and is referenced in kilocalories per minute or kilojoules per minute. To be more appropriate to the individual, oxygen consumption should be expressed relative to body weight. Figure 1 portrays the subcomponents of TEE (discussed in more detail below), and also identifies the commonly used objective assessment techniques to quantify each subcomponent. Each technique will be discussed in detail in a later section.

\section{COMPONENTS OF TOTAL ENERGY EXPENDITURE}

Total daily energy expenditure (TEE or TDEE) is comprised of REE, TEF also referred to as diet-induced thermogenesis (DIT), plus AEE.

Energy expenditure can be estimated by measuring macronutrient or oxygen consumption, or heat production or carbon dioxide production. Most measurement approaches in use today involve the measurement of oxygen consumption and/or production of carbon dioxide via indirect calorimetry. In contrast, direct calorimetry, the measurement of heat production in a metabolic chamber, is not widely utilized.

\section{RESTING ENERGY EXPENDITURE}

Resting energy expenditure or RMR represents the largest proportion of TEE. Simply defined, REE represents the energy expended at rest by a fasted individual in a thermo-neutral environment. $\mathrm{RMR}$ is typically slightly higher than basal metabolic rate (BMR) that is measured under stricter conditions.

Estimation of energy requirements of individuals is typically undertaken by measuring RMR or REE or estimated using 
standard equations then multiplied by a known factor to derive an estimate of PAL.

\section{DETERMINANTS OF REE}

Major factors contributing to individual variation in REE include age, gender, body size, body composition, ethnicity, physical fitness level, hormonal status, and a range of genetic and environmental influences (21-25). Following is a brief overview of the first four determinants.

\section{AGE}

Typically, RMR reduces with age as a function of biological changes (26-28) including loss of lean body mass and associated metabolic activity (29).

\section{GENDER}

The bulk of the gender differences in REE are explained by differences in body composition with the typical adult female having more fat in proportion to muscle than males (21). Females have a metabolic rate $5-10 \%$ lower than males of the same height and weight. Reductions in REE occur later in women, at $\sim 50$ years of age compared to 40 years in men (27), and values are lower in women even after adjusting for differences in body composition $(30,31)$.

\section{BODY SIZE}

Bigger individuals have more tissue and hence, higher energy requirements (greater metabolic activity) than smaller individuals. In addition to age, gender, body size, and body composition (proportion of fat and muscle), a range of factors can also contribute to inter-individual differences in metabolic rate including genetics, growth and repair of body tissues, ethnicity, and the environment.

\section{BODY COMPOSITION}

Body composition plays a significant role in REE with the primary determinant being fat-free mass (FFM) (24). Therefore, most of the inter-individual variability in REE can be accounted for by differences in FFM (22). Along with age and gender, physical fitness has a major influence on the amount and proportion of FFM.

\section{CALORIMETRY}

Human energy metabolism involves the production of energy from the combustion of fuel in the form of carbohydrate, protein, fat, or alcohol. In this process, oxygen is consumed and carbon dioxide is produced. The measurement of EE involves the measurement of heat production or heat loss directly, referred to as direct calorimetry. The measurement of a proxy of heat production or loss by measuring oxygen consumption and/or carbon dioxide production is called indirect calorimetry (32). Early calorimeters for the measurement of human EE were direct calorimeters; however, most measurement of EE today is via indirect calorimetry.

A relatively small number of metabolic (or respiratory) chambers are in use globally, however, there has been a resurgence in interest and increase in numbers in recent years (33). Such chambers are used to assess EE energy over extended periods, from 24-h to a number of days, and provide accurate measures of 24-h and sleeping EE plus long-term substrate utilization. However, because of the confined space, chambers do not provide an accurate estimate of an individual's free-living AEE.

Metabolic chambers and small metabolic carts with ventilated hood systems are similar in their requirement of the measurement of $\mathrm{CO}_{2}$ and $\mathrm{O}_{2}$ concentrations and flow rate to calculate oxygen consumption, carbon dioxide production, respiratory exchange ratio (RER), and metabolic rate (34-36). Both systems measure oxygen consumption and carbon dioxide production continuously and this enables the accurate determination of energy production under controlled laboratory conditions.

Measurements with a ventilated hood are typically performed over a minimum of 30-min to several hours to determine REE or TEF. Measurements using a metabolic chamber typically last from a number of hours to several days and allow the determination of REE, TEF, and AEE for (standardized) PA. Typical ventilated hood systems use a transparent plastic canopy that encloses the head. Room air is drawn through the hood and the flow and concentration of oxygen and carbon dioxide in the intake and expired air are accurately measured and REE calculated (37). In summary, this approach is a form of indirect calorimetry as heat is not directly measured. Rather, the approach measures $\mathrm{O}_{2}$ consumption and $\mathrm{CO}_{2}$ production, which are then used to calculate EE.

Whole-room metabolic chambers or calorimeters provide accurate measurement of REE but as mentioned above, are less accurate in the assessment of the energy cost of PA undertaken in the chamber, typically due to physical constraints imposed by the size of the chamber. Most whole-body indirect calorimeters are $\sim 15 \mathrm{~m}^{3}$ in volume and contain basic furniture such as a single bed, chair, table, television, exercise bicycle, sink, and toilet. EE calculations from $\mathrm{O}_{2}$ and $\mathrm{CO}_{2}$ exchanges typically use the equations of Livesey and Elia (38). Very recently, Lam et al. (33) developed a set of equations to prescribe and adjust energy intake to achieve energy balance in respiratory chambers over 24-h.

Methods of indirect calorimetry are the most commonly used to quantify human EE in both laboratory and field settings, typically by measuring $\mathrm{O}_{2}$ consumption. This approach is based on the relationship between $\mathrm{O}_{2}$ consumption and energy produced, i.e., for each liter of $\mathrm{O}_{2}$ consumed by the body, the equivalent of $\sim 5 \mathrm{kcal}$ is utilized. In simple terms, by measuring $\mathrm{O}_{2}$ consumption during defined tasks such as resting, standing, walking, and running, the energy cost or energy expended can be determined.

\section{DOUBLY LABELED WATER TECHNIQUE}

The DLW technique is widely acknowledged as the criterion or "gold standard" approach to assess TEE (39-41). The technique is applicable in a wide range of populations including the most vulnerable such as pregnant and lactating women and infants. Importantly, the technique is suitable for use in a free-living context, is non-invasive and imposes minimal participant burden. TEE is typically assessed over a 7- to 14-day period (depending on the analysis approach and age of participant). Another major advantage is the accuracy and precision of the technique.

Despite being the criterion method for the assessment of TEE, the DLW technique does not provide specific information regarding daily PA (11). In short, the technique provides an accurate measure of TEE over a chosen number of days or weeks from which 
average daily EE can be calculated, but does not quantify activity type, intensity, or duration accounting for this EE (10). Similarly, as the analysis of biological samples (commonly urine) for the technique requires the use of sophisticated laboratory-based equipment, the combined cost of isotopes, and the analysis of samples is a potential impediment for large-scale studies. Despite these limitations, there is great scope for further use of this "gold standard" technique. Importantly, a further illustration of the utility of the technique is its use to validate other approaches for the quantification of free-living EE $(14,42)$. A recent paper confirmed the reproducibility of the DLW technique in longitudinal studies and validity of the technique to define energy intake plus monitor adherence and body composition changes across periods ranging from 2.5 to 4.4 years (43).

In the DLW technique, daily urine samples are collected over a 7- to 14-day period and subsequently analyzed using isotope ratio mass spectrometry (IRMS) (40). The stable isotopes, deuterium $\left({ }^{2} \mathrm{H}\right)$ and oxygen-18 $\left({ }^{18} \mathrm{O}\right)$ are administered orally via a drink of water, and elimination of the isotopes from the body is tracked (44-46). The difference between the elimination rates of ${ }^{2} \mathrm{H}$ and ${ }^{18} \mathrm{O}$ is equivalent to the rate of carbon dioxide production that can then be converted to average TDEE (47). Readers are encouraged to access a number of recent International Atomic Energy Agency (IAEA) publications for a detailed overview of the DLW technique for the assessment of TEE and other isotopic techniques in nutrition (40) and also recent papers in the area (44).

Components of TEE, including REE, are measured via indirect calorimetry (or using prediction equations) (48-50). This enables the subsequent calculation of AEE (assuming that TEF constitutes $10 \%$ of TEE):

$$
\operatorname{AEE}(\mathrm{kcal} / \text { day })=0.9 \times \operatorname{TEE}(\mathrm{kcal} / \text { day })-\operatorname{REE}(\mathrm{kcal} / \text { day })
$$

Activity energy expenditure represents all energy expended above the resting level and energy costs associated with the ingestion and assimilation of food. AEE is a direct measure of the energy cost of PA and may be used to measure the energy cost of a specific task (as kilocalories per minute or kilojoules per minute) OR to estimate average EE (13):

$$
\begin{aligned}
\operatorname{AEE}(\mathrm{kcal} / \text { day })= & \text { total EE }(\mathrm{TEE} ; \mathrm{kcal} / \text { day }) \\
& - \text { Resting EE }(\mathrm{REE} ; \mathrm{kcal} / \text { day })
\end{aligned}
$$

Activity energy expenditure is also influenced by body weight such that larger (heavier) individuals expend more energy at a given speed than smaller individuals. Exercise economy, or the efficiency of performing a movement task, also impacts EE (13).

As mentioned above, daily AEE can be calculated as an average across the DLW monitoring period, however, the technique does not provide any information regarding the mode, intensity, or duration of PA. Accordingly, we need to utilize a range of other objective measures to predict AEE and PAL.

\section{PHYSICAL ACTIVITY LEVEL}

Physical activity level is the ratio of TEE to REE (or BMR) and provides an index of the average relative excess output related to
PA (intensity $\times$ duration) for a 24 -h period (13) with TEE commonly derived using the DLW technique. The validity of PAL has been tested and confirmed in a large sample (51) and when derived from DLW data, the index is relatively accurate but expensive. Less expensive is the estimation of TEE using HR data, as discussed in a later section (13). Some have queried the relevance of a ratio between TEE and REE if PAL is not independent of body weight (52). In population studies, PAL is calculated by dividing total energy intake by an estimate of REE with total energy intake serving as a surrogate of TEE and assuming individuals are in energy balance. REE is measured or predicted from age, gender, height and weight (13).

Physical activity level can also be used to estimate total daily energy requirements of a population by assuming an average PAL for the group being studied. For example, a PAL equivalent to 1.56 would predict an average energy requirement of $\sim 2000 \mathrm{kcal} /$ day for women weighing $55 \mathrm{~kg}$ (53). The index has also been used to verify the accuracy of self-reported energy intake (54), that is, below a certain threshold $(\mathrm{PAL} \times 1.2)$ the index suggests that energy intake is underestimated (13).

In well-nourished adults, the average PAL is a major determinant of energy requirements. PAL can be measured or estimated from average values of $24-\mathrm{h}$ TEE and REE:

$$
\mathrm{PAL}=\mathrm{TEE} / \mathrm{REE}
$$

Typical PAL values in free-living adults range from 1.40 to $\sim 2.40$.

\section{METABOLIC EQUIVALENT}

One MET equates with the oxygen consumption $\left(\mathrm{O}_{2}\right)$ required at rest or sitting quietly and is assumed to be $3.5 \mathrm{~mL} / \mathrm{O}_{2} / \mathrm{min} \times \mathrm{kg}$ body weight. The index is used to express $\mathrm{O}_{2}$ uptake or intensity of activities as multiples of the resting or 1 MET value and is useful for describing and prescribing exercise of different intensities $(13,55)$.

Comprehensive lists of EE estimations for numerous physical activities have been developed and published in a Compendium $(17,56,57)$. This enables the estimation of daily EE by converting time spent in PA to energy equivalents. Activities range from 0.9 MET (sleeping) to 18 METs (running at $10.9 \mathrm{mph}$ ) (13). This classification system is particularly useful for epidemiological studies as MET scores can be ascribed to individuals according to their self-reported PA levels (58). However, the actual energy cost will vary between individuals due to differences in body mass, adiposity, age, gender, and environmental conditions (17). To allow for differences in body weight, the MET is generally expressed in terms of $\mathrm{O}_{2}$ uptake per unit body mass: $1 \mathrm{MET}=\sim 3.5 \mathrm{~mL} / \mathrm{O}_{2} / \mathrm{min} / \mathrm{kg} \times$ $\min (55)$.

As $5 \mathrm{kcal}$ is $\sim 1 \mathrm{~L}$ of oxygen consumed, $1 \mathrm{MET}$ is equivalent to $\sim 1.0 \mathrm{kcal} / \mathrm{kg} \times \mathrm{h}$ OR $4.184 \mathrm{~kJ} / \mathrm{kg} \times \mathrm{h}$.

The precision of this factorial method to quantify EE is influenced by two main factors. PA estimates are only as good as the information recorded, therefore, the accuracy of an individual's recall of PA completed is a major influencing factor $(55,59$ 61). Secondly, EE estimates are influenced by the accuracy of the assigned MET level and the underlying premise of the factorial system, that is, the consistency of the assumed resting value of 
$3.5 \mathrm{~mL} / \mathrm{O}_{2} / \mathrm{min} \times \mathrm{kg}$ body weight for individuals of different size and shape.

It is important to remember that the Compendium was developed to classify PA and standardize MET intensities in population health research, not to determine the precise energy cost of PA $(17,19,56,57)$. The MET system is widely used by researchers, clinicians, and practitioners; however, increasing evidence suggests that estimates of AEE using the factorial system may be inaccurate across individuals of different body mass and body fat category. In a heterogeneous sample of 769 weight-stable and healthy adults (18-74 years of age, $35-186 \mathrm{~kg}$ ), the 1 MET value of $3.5 \mathrm{~mL} / \mathrm{kg} \times$ min overestimated the actual resting $\mathrm{VO}_{2}$ value by an average of $35 \%$ and the $1 \mathrm{MET}$ of $1 \mathrm{kcal} / \mathrm{kg} \times \mathrm{h}$ overestimated REE by $20 \%$ (18). Very recently, Wilms et al. (62) confirmed that the commonly used 1 MET value largely overestimated EE in overweight to obese individuals and produced BMI-specific MET correction factors.

In summary, the most common utilization of the MET has been to categorize PA intensity. Moderate PA is defined as 3-6 METs, moderate-to-vigorous $\mathrm{PA}$ as $>3 \mathrm{METs}$, and vigorous $\mathrm{PA}$ as $>6$ METs (3).

\section{HEART RATE MONITORING}

Estimation of EE and PA via HR monitoring is popular, convenient, relatively inexpensive, non-invasive, and versatile. Along with pedometers and accelerometers, HR monitors are major examples of objective measurement (63). Monitoring HR minuteby-minute enables detailed information on frequency, intensity, and duration of free-living PA (13).

\section{MEASURING ENERGY EXPENDITURE}

Heart rate monitoring is used to estimate EE based on the assumption of a linear relationship between $\mathrm{HR}$ and oxygen consumption $\left(\mathrm{VO}_{2}\right)$. Despite considerable inter-individual variability in the slope of the $\mathrm{HR}-\mathrm{VO}_{2}$ relationship, the linear relationship is consistent for an individual across a range of submaximal tasks $(64,65)$. Inter-individual differences are predominantly a reflection of differences in movement efficiency, age, and fitness.

The relationship between HR and EE for an individual is established using a sub-maximal calibration procedure typically undertaken immediately following the assessment of REE. HR and breath-by-breath $\mathrm{VO}_{2}$ and $\mathrm{VCO}_{2}$ are measured (averaged over 10-s intervals) using a metabolic cart in the following sequential steps: 5-min sitting, 5-min standing, 5-min cycling at low resistance $(55 \mathrm{~W})$, and further 5 -min blocks of increasing cycling resistance while maintaining a cadence of $60 \mathrm{rpm}$. Cycling resistance is increased by $50 \mathrm{~W}$ in each subsequent 5 -min block until the participant has cycled for at least three incremental stages, depending on level of fitness, and HR has reached $\sim 150$ beats/min. Average EE for each activity and at each workload is estimated from $\mathrm{VO}_{2}$ and $\mathrm{VCO}_{2}$ values using the equations of Livesey and Elia (38). To equate $\mathrm{HR}$ to $\mathrm{EE}$, a regression line of $\mathrm{HR}$ to $\mathrm{EE}$ is developed for each individual from the sub-maximal calibration procedure and using measurements for sitting, standing, and at each of the workloads. The critical HR, below which the relationship between HR and EE is non-linear (flex-HR), is calculated from the mean of the highest HR when the participant was standing, and the lowest HR when exercising (66).

Consequently, once an individual or group regression line has been calculated, HR can be used to estimate oxygen consumption and $\mathrm{EE}$ in free-living conditions. A wide range of HR monitors, varying in sophistication and function, are now used in different contexts (67). Many HR monitors have significant storage capacity and the ability to record average HR data in 5-s or 1-min blocks across a week (68). A major advantage of using HR monitoring at the individual level is the ability to calibrate the monitor to the individual. Individualized $\mathrm{HR}-\mathrm{VO}_{2}$ regression equations provide greater accuracy as they account for individual differences in health and fitness.

However, the method has important limitations. Because the relationship between $\mathrm{HR}-\mathrm{VO}_{2}$ differs between upper-body and lower-body activities (69), the use of a single regression line derived from an activity such as walking or running will not be accurate for other activities. Further, while there is a very close relationship between HR and EE during exercise, this is not the case during rest and light activity $(11,66,70)$. This problem can be overcome using the flex-HR method that utilizes an individually predetermined HR to discriminate between resting and exercise HR (71). HR monitoring has been validated for measurement of EE in controlled settings $(72,73)$ and free-living contexts $(74,75)$ in young people (5).

\section{MONITORING EXERCISE INTENSITY}

A major advantage of HR data is the ability to quantify the intensity of exercise and estimate EE in continuous or steady state aerobic exercise. HR levels to describe exercise intensity should be expressed as $\% \mathrm{HR}_{\text {Reserve }}$ and/or $\% \mathrm{HR}_{\max }$ enabling exercise intensity to be classified into six categories from very light to maximal (76). Using such an approach, it is possible to equate the HR category with its associated $\% \mathrm{VO}_{2 \max }$ or $\% \mathrm{VO}_{2 \text { Reserve }}$ or MET and not require the measurement of $\mathrm{VO}_{2}$. However, it is much more accurate if the $\mathrm{VO}_{2}-\mathrm{HR}$ relationship is measured for each individual as outlined above (68).

In summary, HR is a major physiological marker for PA but is influenced by a wide range of factors unrelated to the activity being monitored. As such, HR provides an estimate or overview of PA but estimates can be improved if used in conjunction with other devices such as accelerometers (11).

\section{MOTION SENSORS PEDOMETERS}

Pedometers are arguably the most popular and widely utilized form of motion sensor. Pedometers register steps taken during walking and running activities and have been popularized as a motivational tool to encourage sedentary or inactive individuals to become more physically active. PA targets in "steps per day" including the commonly used adult benchmark of "10,000 steps," is well-understood by the lay public. Recent interest in the use of pedometers includes the relevance of cut-points, in particular their equivalence with $\mathrm{EE}$ in different populations. The rationale for targets and cut-points, including 10,000 steps/day, has been challenged as a recommendation for some groups (77). For example, 30-min of brisk walking per day equates to 3-4000 steps or 
Table 1 | Number of steps per day and corresponding physical activity level.

\begin{tabular}{ll}
\hline Physical activity level & Steps per day \\
\hline Sedentary or inactive lifestyle & $<5000$ \\
Low active & $5000-7499$ \\
Somewhat active & $7500-9999$ \\
Active & $10,000-12,500$ \\
Highly active & $>12,500$ \\
\hline
\end{tabular}

1250-1550 steps/km (78). Table 1, modified from Tudor-Locke and Bassett (4), uses data from a range of studies and can also be used to categorize PA level based on step counts.

A large and increasing number of pedometers are available. As devices vary widely in sophistication of function and reliability, readers are referred to a number of relevant publications for further information (79-83).

Objective evaluation of pedometers has identified numerous shortcomings in accuracy. For example, pedometer step counts are more inaccurate at slow speeds $(<60 \mathrm{~m} / \mathrm{min})(84)$ therefore, may be inappropriate for work with older adults $(85,86)$. Pedometer readings can also vary according to where the pedometer is mounted or "worn" $(84,87,88)$. For example, in centrally obese individuals with a large waist circumference, pedometers may rotate if worn in the standard position on the waistband (89, 90). Foot strike also varies between and within individuals so that when a pedometer is worn by different individuals, it may register a different step count for the same number of actual steps taken, presumably due to a differential between the foot strike of left and right legs (91).

Most pedometers fail to account for individual differences in height and leg length. Step count is also influenced by stride length (commonly related to both height and leg length) and speed of walking (87). If an individual walks faster than normal, a pedometer may underestimate total distance walked. Alternatively, pedometers may overestimate distance when walking slower than customary unless there are commensurate relative changes in stride length and step frequency when speed changes. The implications are that step count should not be used as a proxy for distance traveled without calibration of the pedometer to know how many steps an individual takes over a given distance. Calibration at a range of speeds may also be warranted. The ActiGraph accelerometer, the anterior mounted New Lifestyles, and the Walk4Life motion sensors have acceptable step count error values during treadmill walking at a range of speeds (84).

Pedometers have also been criticized for their ability to be manipulated to increase the total number of steps recorded. Simply shaking many devices will increase step count when the movement is clearly not associated with walking steps. Similarly, young people and other inquisitive participants may regularly look at the number of steps taken and alter their "typical" pattern of activity in order to increase the step count. To avoid or discourage such manipulation researchers often tape over the device to reduce any feedback based on step count. To increase the likelihood that monitoring is a reflection of a typical day, researchers often discount data collected on the first and last few days of a block of measurements.

Major advantages of pedometers are that they are relatively inexpensive, easy to use, and output data can be used to raise awareness regarding level of PA, including motivation for increased PA. As walking is such a common form of light- to moderate-intensity PA, a good measure of distance and speed is important. Similarly, if pedometers are used in an intervention or as a tool to monitor changes in daily PA, the sensitivity of the tool to measure change should be high. Tudor-Locke and Myers (92) reported that pedometers were able to track modest increases in walking volume in obese sedentary adults involved in an intervention, whereas PA diaries were not sensitive to the change in ambulation. Unfortunately, many sub-standard pedometers are available therefore selection of device for reliable measurement of steps should be considered carefully.

\section{ACCELEROMETERS}

Accelerometers are motion sensors that detect accelerations of the body. Acceleration is defined as the rate of change in velocity over a given time; therefore, the frequency, intensity, and duration of PA can be assessed as a function of body movement (93). Accelerometers consist of piezoelectric transmitters that are stressed by acceleration forces. This leads to the production of an electrical signal that is subsequently converted by processing units to produce an indication of movement (15).

Accelerometers have gained considerable popularity in recent years as an objective approach to measure daily PA and represent a substantial improvement over self-report methodologies (3, 6, 94, 95). Accelerometry enables an estimation of intensity and duration of movement and the relationship between accelerometer counts and energy cost allows PA to be classified by intensity $(13,95-97)$. Numerous papers $(5,98-102)$ have reported that accelerometers are objective, practical, non-invasive, accurate, and reliable tools to quantify PA volume and intensity with minimal discomfort (95, 103-105). Technological advancements in accelerometry mean that the popularity and accessibility of this methodology has increased steadily such that it may be the preferred objective approach to assess PA and EE $(95,106,107)$.

There is also increasing interest in the objective measurement of sedentary behaviors (or physical inactivity) (108). Sedentary behaviors include purposeful involvement in activities involving minimal movement and low levels of PA (108-110). However, this review does not detail the measurement of sedentary behavior and readers are referred to a number of recent publications in the area $(111,112)$.

Accelerometers provide information (outputs) regarding body movement in counts per unit time (referred to as an epoch). Importantly, movement counts have no biological meaning per se and must be converted to more relevant constructs (108), typically based on intensity. These include moderate-to-vigorous physical activity (MVPA) or sedentary behavior, or direct observation of PA, or some health outcome in calibration studies $(113,114)$. Rate or intensity of movement is captured using piezoelectric sensors to detect acceleration in one plane (uni-axial), two planes (biaxial), or three orthogonal planes (tri-axial) representing vertical, 
anteroposterior, and mediolateral directions $(15,101)$. Accelerometers are more sophisticated and therefore superior motion sensors than pedometers.

Examples of uni-axial accelerometers include the ActiGraph wGT3X-BT (Actigraph LLC, Pensacola, FL) and Personal Activity Monitor - PAM AM200 (PAM B.V. Doorwerth, Netherlands) and bi-axial accelerometer - ActiTrac (IM Systems, Baltimore, $\mathrm{MD})$. These sensors are typically worn so that the sensitive axis is oriented to measure vertical acceleration and deceleration (101). Accelerometers such as Actical (Philips Respironics, Bend, OR) can record movement in all directions however are most sensitive in the vertical plane $(93,101)$. In contrast, tri-axial accelerometers such as the Personal Activity Monitor - PAM AM300 (PAM B.V. Doorwerth, Netherlands) and RT6 (Stayhealthy Inc., Monrovia, CA) measure movement in three planes (15).

Tri-axial accelerometers arguably provide a more comprehensive assessment of movement representative of PA than uni-axial accelerometers. This may be particularly the case in children as the devices may be more sensitive to some activities including climbing and jumping (72). Hendelman et al. (85) reported that tri-axial accelerometers have a higher correlation than uni-axial devices with $\mathrm{EE}$ in adults.

Major advantages of accelerometers include their relatively small size and capacity to record data continuously over an extended period (days or weeks) $(11,15,107)$ and lack of visual feedback to the individual wearing the device. The lack of immediate feedback means that the likelihood of an overestimation of $\mathrm{PA}$ (such as is possible with the manipulation of a pedometer) is reduced. Simple uni-axial accelerometers contrast with more sophisticated and precise tri-axial devices, particularly regarding estimation of EE (11).

Accelerometry has enabled both PA and sedentary behaviors to be measured with greater accuracy and precision $(115,116)$ than in older studies using subjective methodologies to quantify PA $(3,108,117)$. A number of large-scale studies have successfully used accelerometry to assess PA in youth $(116,118)$ and increasingly accelerometry has been utilized in studies of very young children (104).

Accelerometry is based on the fact that speed is the change in position with respect to time, and acceleration is the change in speed with respect to time. Acceleration is typically measured in gravitational acceleration units $\left(\mathrm{g} ; 1 \mathrm{~g}=9.8 \mathrm{~m} / \mathrm{s}^{2}\right)$. When acceleration is zero, speed does not change, however, movement may still occur but at a constant speed. Because acceleration is also proportional to the net external force involved, it more directly reflects the energy costs associated with the movement. Accordingly, measurement of PA using acceleration is preferred to using speed. More detailed technical aspects of accelerometry are also not the focus of this review but are available from a number of authoritative sources $(15,119,120-122)$.

Despite a good linear relationship between accelerometer counts and EE during walking, some concerns have been reported in studies of running. For example, Brage et al. (123) assessed the reliability and validity of the CSA (model 7164) accelerometer (MTI) across a wide range of walking and running speeds in laboratory and field settings and noted that the CSA output rose linearly $\left(R^{2}=0.92\right)$ with increasing speed until $9 \mathrm{kph}$ but remained at $\sim 10,000$ counts/min during running. Therefore, oxygen uptake is underestimated at speeds $>9 \mathrm{kph}$. Authors proposed that the lack of linearity may be due to a relatively constant vertical acceleration in running. Rowlands (101) reported similar findings from comparisons of uni-axial (ActiGraph) and tri-axial (RT3) devices and confirmed that activity was underestimated as speed increased using a uni-axial device with acceleration only assessed in the vertical plane. Rowlands (101) found that output from tri-axial devices was strongly related to speed, a reflection of the predominance of horizontal acceleration at higher speeds. Improvements in technology have resulted in single devices (124) measuring and reporting movement in all three axes separately and simultaneously (RT3). This study assessed whether using three planes of acceleration signals is superior to using only the vertical plane of the same unit for predicting AEE during locomotion and activities of daily living (ADL). The tri-axial capacity did not significantly improve the relationship between movement counts and AEE compared with uni-axial devices.

Another important comparison is between accelerometry outputs and indirect calorimetry. The RT3 motion sensor overestimated AEE for treadmill activity by $9 \%$ and underestimated ADL by $34 \%$. The RT3 underestimated activity with greater upper-body movements by $24-64 \%$. Compared to DLW assessed over 15 days and using the proprietary algorithms, Maddison et al. (125) found the RT3 underestimated AEE by $15 \%$ on average. While the RT3 provided a relatively accurate assessment of free-living AEE at the group level, it generally underestimated the AEE compared to DLW. These studies demonstrate that is not sufficient to only consider the number of axes used, but rather the technology inherent in the device or the data processing available. Plasqui et al. (126) noted that age, body mass, and height collectively explained $64 \%$, while the tri-axial accelerometer (Tracmor) added only an additional $19 \%$ of the variation in TEE. In some studies, it is possible that most of the variance is explained by participant descriptors and the accelerometry data may have only marginal additional value. Few studies have provided data to demonstrate the ability of the accelerometer to predict individual AEE rather than AEE on a group level only; standard errors or limits of agreement should be presented. Plasqui and Westerterp (120) outline an important range of issues for consideration when comparing the validity of different accelerometers.

Irrespective of the use of accelerometry counts to convert to $\mathrm{EE}$, a major advantage of the technique is the ability to quantify time spent in activities of different intensities. Accelerometer outputs are typically related to standard thresholds for activity of light, moderate, and vigorous-intensity (127-129). However, a major issue in the field is how to select cut-off points to define activity intensities. Despite a number of proposed cutoffs for some devices, there is currently no consensus $(3,130)$. If there is inconsistency in the use of accelerometers and cutoffs to delineate exercise or PA intensity, it is extremely difficult to make meaningful comparisons between the findings of different studies (106). Similarly, uniform cut-off points may not be truly representative of the same exercise intensity across individuals.

The most widely used accelerometer in studies of children and adolescents is the ActiGraph; however, the ranges for defining the 
lower limit for different intensities are considerable $(3,75,131$, 132). Most studies (133-135) have used a lower threshold for moderate PA and vigorous PA as suggested by Trost et al. (73), whereas some studies (136) have used a significantly higher cutoff point for moderate and vigorous-intensity PA as suggested by other validation studies $(131,137)$.

Accelerometers are most commonly worn on a waist belt and aligned with the right anterior axillary line and worn at all times for up to 7 days except when showering, bathing, swimming, or involved in contact sports. It is also useful to encourage participants to keep a record of when they removed the monitor for any reason. A common epoch length is 30-s with a minimum wear time defined as 10-h/day for 4 of the 7 -days, one of which must be a weekend day (138). Non-wear time should also be specified, for example 60-min of consecutive zero counts. Total counts and minutes spent in sedentary, light, moderate, and vigorous-intensity PA can be calculated using the Actilife 5.5 software (ActiGraph, Pensacola, FL, USA) plus published cut-offs, for example, as described by Troiano et al. (139) for adults. In adults, the hip-mounted ActiGraph has demonstrated high inter-device reliability ( $r=0.98)$ (123) and validity against indirect calorime$\operatorname{try}(r=0.56, p<0.001)$ (129) and least variability when compared with other accelerometers (140).

Accelerometers have low sensitivity to sedentary activities and are unable to register static exercise (122). Similarly, as accelerometry is insensitive to PA that does not involve a transfer of the center of mass at a rate relative to the energy expended (e.g., weight lifting, walking up a slope, walking, and carrying a load), this will lead to errors in measurement of TEE $(129,141)$.

Like all methodologies, accelerometers have a number of limitations including the possibility of reactivity based on the individual knowing they are being monitored (3). If accelerometers are used for a limited number of days, these may not be representative of the individual's habitual PA. Because accelerometers display interand intra-monitor variability, it is strongly recommended that trials are undertaken to identify outlying monitors and understand the inter-monitor variability before commencing a study (142). Further, as outlined above, accelerometers should be calibrated to each individual user. To improve the categorization of movement, some studies have used multiple accelerometers worn on different body parts (trunk, chest, wrists, legs, and feet). Whole-body EE can be determined from the composite of movements. Heil et al. (143) developed good guidelines and a very useful decision-making algorithm associated with accelerometry. Similarly, Mannini et al. (144) developed an algorithm to process wrist and ankle raw data from a single accelerometer to classify behavior into ambulation, cycling, sedentary, and other activities.

In very young children ( $<5$ years), accelerometers and direct observation are well-established as the preferred PA monitoring approaches $(96,104)$ as they can detect short bursts of activity typical at this age $(104,145)$. However, the validity, reliability, and feasibility of accelerometry in toddlers ( $<3$ years) have only recently been addressed $(103,145)$ and much more work is required in this area (107). The study by Van Cauwenberghe et al. (107) was one of the first to assess the feasibility of ActiGraph accelerometer assessment of PA in toddlers and the appropriateness of using accelerometer cut-points proposed for older children. ActiGraph accelerometers are the most widely used for PA research in children and adolescents $(108,145,146)$.

In studies with young children, accelerometers have been programed to record data every $15-\mathrm{s}(101,103,108)$ and Meterplus 4.2 software used to screen and clean data (Santech). It is also commonplace to omit data from both the first and the last day of the registration period (97) and periods of $>10$-min of consecutive zero activity counts regarded as non-wearing time and excluded $(97,103,147)$.

The minimum number of minutes with recorded accelerometer data (registration time) required to constitute an eligible weekday and weekend day has been determined by defining the period during which at least $70 \%$ of the study population had recorded accelerometer data and $80 \%$ of that observed period constituted the minimum registration time $(97,102,147)$. Days on which participants did not achieve the minimum registration time are considered as non-eligible days and are excluded. Minimum registration time has been defined separately for weekdays and weekend days as this often varies (101-103). If data are available for three valid days, this information is analyzed (103).

ActiGraph cut-points to define PA intensities for 3-5 year-olds $(148,149)$ are as follows: sedentary behavior: $\leq 37$; light physical activity (LPA): 38-419; and MVPA: $\geq 420$. Cut-points for 3year old children (132): sedentary behavior: $\leq 301$; LPA: 302-614; MVPA: $\geq 615$. Cut-points by Van Cauwenberghe et al. (147) for 5-year old children were: sedentary behavior: $\leq 372$; LPA: $373-584$; and MVPA: $\geq 585$.

Van Cauwenberghe et al. (95) found that the Pate cut-points can be used to classify sedentary and non-sedentary behavior in toddlers. However, none of the three sets of cut-points for preschool children appeared suitable to differentiate light and moderate-tovigorous PA in toddlers. Without suitable equations for toddlers, Van Cauwenberghe et al. (95) suggest that accelerometer counts (i.e., counts per minute) be used as a measure of PA participation.

\section{COMBINED APPROACHES}

As no single technique is able to quantify all aspects of PA under free-living conditions, use of multiple complementary methods is recommended (13). For example, a potentially powerful approach to quantifying EE is the simultaneous use of accelerometry and HR monitoring $(5,11,73,141,150)$. The rationale for combining these techniques is that accelerometer counts verify that elevations in $\mathrm{HR}$ are due to PA. As mentioned above, the relationship between $\mathrm{HR}$ and $\mathrm{EE}$ is influenced by a host of factors including age, gender, level of training, stroke volume, temperature, etc. (151). Limitations of accelerometry include the inability of the device to account for additional load carried by the user (5) and changes in the grade of the exercise surface. The fact that the two sets of limitations are completely different suggests that a more precise estimation of EE may be possible with a combined approach (141).

As mentioned in the section on $\mathrm{HR}$ monitoring, the $\mathrm{HR}-\mathrm{VO}_{2}$ relationship is only linear during moderate to high-intensity exercise (152). Therefore, HR monitoring is useful to quantify PAEE but not the low-intensity PA characteristic of a large proportion of the total daily PA undertaken by many individuals. Accelerometry may be considered as the reverse, very limited in the assessment of AEE but able to quantify low levels of PA or sedentary behavior 
(73). As a combined HR and movement sensor, Actiheart exploits the advantages of each technology in a single device. Actiheart has been validated in adults during treadmill walking and running for the prediction of PAEE (153) and Corder et al. (5) has confirmed the same in children. Examples of combined movement counter and HR monitor include Actiwatch/Actiheart/Actiband; and ActiTrainer. A number of the more complex devices, including the SenseWear Armband, are discussed in a following section.

Examples of prominent international companies producing HR monitors include Polar ${ }^{1}$, Suunto ${ }^{2}$, and Garmin ${ }^{3}$. A growing range of products with more sophisticated features are available and not discussed here. These include the capability of collecting data on both physiological and mechanical variables including distance, speed, altitude, cycling power output, running pace and cadence, altimeter features, GPS features, and cycling and running features. Increasingly, smartphone applications will provide the new opportunities for monitoring, including the quantification of non-wear time of objective devices such as accelerometers (154, 155). Discussion of these new approaches is beyond the scope of the current review.

\section{SENSEWEAR ARMBANDS}

The SenseWear armband ${ }^{4}$ collects data from multiple sensors: a skin temperature sensor, near-body temperature sensor, heat flux sensor, galvanic skin response sensor, and a bi-axial accelerometer. The combination of signals from these sensors enables the assessment of activity type and intensity and the incorporation of detail regarding age, gender, height, and weight enables EE to be estimated using proprietary algorithms. Readers are referred to a number of recent validation studies (156-158).

\section{INTELLIGENT DEVICE FOR ENERGY EXPENDITURE AND ACTIVITY}

The intelligent device for energy expenditure and activity (IDEEA) (MiniSun) estimates EE from 35 postures and activities and it can identify and record (159) using multiple sensors. A detailed overview of the device is available in the papers by Zhang et al. $(160,161)$. Much of the published work using the device has been laboratory-based, either validation studies of EE (160) or highly controlled, short duration gait and posture analyses (161-163). The device has also been used to measure patterns of PA and estimate EE over 3 days in a free-living subset of participants in the DiOGenes study (164). A comprehensive assessment by Whybrow et al. (159) evaluated the IDEEA to estimate EE against both wholebody indirect calorimetry, and DLW. The study also compared EE estimates from measured and estimated calibration values.

Compared to indirect calorimetry reference methods, Whybrow et al. (159) reported that the IDEEA significantly overestimated EE outside the laboratory but this overestimate is not always apparent under controlled conditions (161). Using the IDEEA in a calorimeter, Whybrow et al. (159) found the device underestimated the EE of slow walking and overestimated faster walking. In contrast, others have reported better agreement when used in

\footnotetext{
${ }^{1}$ http://www.polar.fi

${ }^{2}$ http://www.suunto.com

${ }^{3}$ http://www.garmin.com

${ }^{4}$ http://www.bodymedia.com
}

a more natural walking motion (165), including a treadmill, than was possible in the calorimeter.

Limitations of the IDEEA system include the relative difficulty of attaching the sensors, the inconvenience and discomfort of wearing the sensors, and the limited memory capacity. Further, the device is unable to detect cycling as an activity and usually allocates a stationary sitting or standing posture with an estimated EE unrelated to the work completed. Consequently, the IDEEA underestimates the EE of cycling (159) and overall is of similar accuracy in estimating EE to the HR method.

To avoid the cost associated with using multiple devices, and participant and researcher burden, a number of studies have paid greater attention to the identification of activity types based on acceleration data measured with a single accelerometer $(166,167)$. Bonomi et al. $(168,169)$ measured ADL with a single accelerometer in a population of healthy adults and used a decision tree algorithm to identify the activity types performed. The decision tree evaluated attributes (or features) of the acceleration signal. Using DLW as the criterion measure, the identification of types of PA such as lying, sitting or standing, active standing, walking, running, and cycling combined with a simple methodology to define the intensity of activity type, improved the estimation of TEE, AEE, and PAL compared with activity counts.

In summary, improvements in individual and/or multiple sensors has progressively improved the objective assessment of physical activity and energy expenditure. For example, Lyden et al. (170) very recently reported a method to improve the estimation of both free-living active and sedentary behaviours from an accelerometer and validated against direct observation. One of the better studies to assess energy expenditure estimation of several activity monitors consistent with a 4 -h stay in a room calorimeter was undertaken by Dannecker et al. (171). IDEEA and Directlife estimates of energy expenditure were not different to measured energy expenditure. In this study, Actigraph and Fitbit devices significantly underestimated energy expenditure. Adam Noah and colleagues (172) assessed the new Fitbit accelerometers against an indirect calorimetry system (Cosmed K4) and the commercially available Actical devices. They also found that Fitbit underestimated energy expenditure in a number of activities however suggested the device was reliable and valid for monitoring over-ground energy expenditure.

\section{SELECTED SUBJECTIVE MEASURES}

A range of subjective approaches complement the objective measures discussed above. Subjective methods are indirect approaches and typically involve the individual recording his or her own activity (93). These include direct observation, activity diaries, PAQs, and interviews (66), however, here we only address some examples of such approaches. Each approach assesses different dimensions of PA, has a variety of outcome variables, and associated strengths and weaknesses.

The fundamental shortcoming of all subjective approaches is the potential to influence the voracity of the information collected (173). Questionnaires rely on one's recollection of PA and enable a categorization of individuals from sedentary and inactive, through to active or very active. Simply stated, subjective approaches quantify the perception of PA as opposed to PA per se (108) as typically 
questionnaires lack the precision needed to detect PA changes on a day-to-day basis $(174,175)$.

Because of the absence of inexpensive, readily available, noninvasive, valid, and reliable objective technology for the assessment of AEE in large numbers of free-living individuals, many researchers rely on estimates of AEE derived from PAQs (176). However, most PAQs have demonstrated limited reliability and validity (173) and it is questionable whether any are valid for estimating AEE at the individual and group levels (176).

Valid measurement of PA is also very challenging in some populations, including children $<5$ years of age, mainly due to the sporadic and intermittent nature of their movement (100, 104, 108). Proxy reports from parents can be useful for rank ordering young children on PA behavior (97), however, inaccurate estimates of the amount and intensity of PA is a primary concern with this approach $(103,104)$. Cognitive limitations of children younger than 10 years of age also limits the accuracy of questionnairederived PA data from young children (114), therefore proxy reports are commonly used (100).

At the individual level, the validity of data derived from subjective approaches for the calculation of PAEE and MVPA is questionable compared to objective alternatives such as accelerometry and the DLW technique that enable data collection over an extended period of time $(106,177)$. The choice between subjective and objective approaches is typically based on the resources available and the number of participants required for the study. Subjective data from PAQs tend to be more valid at a group level and this combined with the relatively low cost, means that a larger number of people can be surveyed or assessed $(11,14)$.

A fundamental problem in the field is when data derived from a self-report PAQ are converted to units of EE. An appreciation of the variability in MET value is important here. Clearly, it is not feasible to measure the energy cost of activities for each individual in large epidemiological studies (176), hence the Compendium of physical activities is widely used $(17,58,59)$. An important limitation of the Compendium is the reliance on group averages based on assumed body weight or REE and therefore energy equivalents that may not apply to individuals $(18,178,179)$.

In youth, there is no standardized reference to parallel the 1 MET equivalent of $3.5 \mathrm{~mL} / \mathrm{O}_{2} / \mathrm{min}$ for adults (106) despite possible differences for MET multiples for the same activities in children and adults (180). Estimations of EE from self-report PAQs in youth typically use adult-derived standard energy costs of specific activities (17). However, these can be adjusted for the higher REE in children (181). Ridley et al. (182) have developed a Compendium of EE for youth, however, only 35\% of the values in this Compendium are derived from data measured in young people with other values extrapolated from adult data (183). Recent published literature has also provided guidance regarding the relative merits of different PA assessment tools for use in defined populations, including overweight and obese children (183).

Self-report PAQs are often the only feasible way to assess PA in many situations $(106,176)$ particularly in studies involving a large number of participants. Similarly, self-report approaches are important for the assessment of aspects of PA not easily measured objectively, including mode and domain (184). Some PAQs can accurately determine the mode of activity and can be used to rank, group, or categorize PA levels with a degree of confidence $(185,186)$.

While some studies contend that it is possible for self-report PAQs to assess some aspects of MVPA $(187,188)$, most agree that PAQs are less accurate than objective methods for estimating PAEE and MVPA $(11,106,189)$.

Relatively, few validation studies of PAQs have used DLW (185, $186)$ with accelerometry being the most common criterion (184, $188,190)$. Corder et al. (106) were the first to simultaneously assess the validity of estimated PAEE and MVPA from PAQs against both DLW and accelerometry. This approach enabled the assessment of the strengths and weaknesses of self-reported PA not possible when only one criterion method is used. A major finding was that all PAQs consistently underestimated PAEE $(106,177)$. Readers are also referred to a paper by Patterson (191) for an explanation of associations between questionnaires and objective measures and a multi-step process of developing an instrument to measure a construct such as PA. Too often researchers refer to validation when a questionnaire is correlated with an objective measure, however, this does not represent criterion-related evidence of validity (177).

A comprehensive appraisal of the use of PAQs to assess AEE in population-based studies by Neilson et al. (192) is particularly informative. They concluded that despite numerous validation studies (using DLW), the validity of PAQs for AEE estimation remains unclear. Neilson et al. (192) contend that weaknesses in study design and reporting of studies is a major contributing factor, along with a failure to make PAQs freely available. Some reasons for discrepancies in estimates of AEE between PAQs and DLW could include the failure of the PAQ to incorporate key activities and differences in length of time assessed in each approach (192).

\section{PHYSICAL ACTIVITY RECORDS OR DIARIES}

Records or diaries can provide very detailed information regarding activity types and patterns, for example walking, watching television, etc., purpose: for example PA, exercise, occupational, transport, etc., intensity (light, moderate, vigorous), duration (in minutes or hours), frequency (how often), and mode or body position (for example sitting, standing, walking) (2). Detailed recordings enable one to account for PA (or EE) undertaken in relatively short 15 -min time intervals. Over a 24 -h timeframe, one can determine how long an individual engaged in various activities and subsequently translate this into EE predictions using MET values for each task and intensity level (2). As mentioned above, a wide range of physical activities have been coded and published in a Compendium of physical activities that categorizes each task or activity into domains and intensities (commonly based on METs). The Compendium was developed in 1989 and extensively updated in 2000 and again in 2011. A disadvantage of activity diaries is the high participant burden, including the time needed for individuals to record physical activities in blocks of $15 \mathrm{~min}$ across multiple 24-h periods.

\section{MULTIMEDIA ACTIVITY RECALL}

A well-developed use of time measure is the Multimedia Activity Recall for Children and Adults (MARCA). The MARCA is a computerized 24 -h recall tool that asks participants to recall their 
use of time in the previous day from midnight to midnight using meal times as anchor points across the 24 -h period day (138). Participants recall their day in blocks of 5-min or more by choosing from 520 activities organized under different categories including "Self-Care," "Occupation," and "Sport/Recreation." Each activity in the MARCA is assigned a MET value to estimate EE based on an expanded version of the Ainsworth Compendium $(17,58)$.

The MARCA was originally designed for use in children and adolescents (193) but has been modified for use in adults (194). The adult version has test-retest reliabilities of 0.990-0.997 ( $p \leq 0.0001$ ) for MVPA, PAL (average daily rate of EE in METs), sleep and screen time, and convergent validity between PAL (estimated average rate of EE) and accelerometer counts/minute of $\rho=0.72$ (186). A recent comparison with the DLW technique displayed correlations of $\rho=0.70$ for TEE (195).

The MARCA enables a determination of EE based on minutes spent in the following zones: 0.0-0.9 MET (sleep); 1.0-1.9 METs (very light physical activity, VLPA); 2.0-2.9 METs (LPA); 3.0-5.9 METs (moderate physical activity, MPA); and $\geq 6$ METs (vigorous physical activity, VPA). A time-use profile is determined by minutes spent in major "activity sets" including physical activity, computer, active transport, passive transport, quiet time, self-care, socio-cultural, work/study, chores, sleep, and TV/videogames.

\section{PHYSICAL ACTIVITY OUESTIONNAIRES}

Physical activity questionnaires are the most widely used approach to monitor activity levels (14). Global questionnaires are easy to administer and complete; however, most only provide minimal information about activity and simply enable a group to be categorized as "active" or "inactive." Recall questionnaires are longer and provide more detailed accounts of PA including information about frequency and duration of activities over extended periods. The significant variability in PAQs includes the amount of detail provided, length of time assessed, and the extent of supervision required to successfully complete the questionnaire (173). Neilson et al.'s (192) systematic review of PAQs provides a comprehensive appraisal of the strengths and weakness of PAQs and their ability to quantify AEE in relation to DLW.

Physical activity questionnaires are completed over a minimum of a 24-h period and up to 7-days (184). PAQs are commonly more valid when administered in an interview context, either by telephone or face-to-face, however, are notorious for overestimating vigorous $\mathrm{PA}$ and underestimating time spent undertaking ADL (2). Miscalculation of the total volume or intensity of PA may have different implications, for example, in the determination of the dose-response relationship between PA and health. Therefore, it is highly desirable to include objective measures with self-report instruments to minimize intentional or unintentional misreporting of PA. Welk et al. (196) recently reported on the validity of a 24-h PA recall compared with EE using SenseWear Armbands. There was good agreement between approaches; however, PA recall may result in biased estimates of MVPA in adults at the group and individual level. If a combined approach is not possible in the whole cohort, it is highly recommended that both measurement approaches be used in a representative sub-sample. Strengths and limitations of PAQs, with specific reference to individual questionnaires, are outlined in Table 2.
Table 2 | Strengths and weaknesses of self-report PAQs.

\begin{tabular}{ll}
\hline Strengths & Limitations \\
\hline - Able to measure large numbers & - Recall challenges for some \\
of participants at low cost & populations, e.g., children and the \\
- Theoretically, recall does not alter & aged \\
behavior & - Semantics may be an issue, e.g., \\
- A variety of dimensions of PA can & terms like "moderate-intensity" \\
be assessed & may be ambiguous \\
- Can extrapolate to EE & - Dependent upon response rates \\
- Suitable for a wide range of & and ability of participants to \\
populations & follow instructions \\
- Measurement tool can be & - Completeness of answers \\
adapted to suit the population & - Activity choices listed in \\
- Possible to compare results from & questionnaire may not be relevant \\
different locations when using & for some populations \\
the same instrument, e.g., IPAO & - Minimum amount of detectable \\
& change (sensitivity)
\end{tabular}

\section{CONCLUSION}

With so many approaches available, the accurate assessment of PA and quantification of EE can be very challenging. It is important to appreciate that irrespective of the apparent sophistication of techniques, all have inherent strengths and weaknesses. A better understanding of the merits of different approaches should inform decision-making and selection of the best approach for the situation, including for specific populations such as overweight and obese children (183).

Objective measurement approaches have been the primary focus of this review; however, subjective approaches, including diaries and PAQs, have the potential to provide rich descriptive data. However, an acknowledged major shortcoming of subjective approaches is their heavy reliance on an individual's recollection of events. Therefore, depending on the context, such approaches may be prone to under- or over-reporting.

Despite the advantages of objective measures, some approaches and devices, including accelerometry, are inappropriate for the quantification of activities other than walking and running. For example, accelerometers are not able to quantify movement in swimming and cycling.

The ideal scenario is for PA and EE to be measured with research quality tools and approaches. If one is interested in total PA, an understanding of physical inactivity is also important. The measurement of total PA or EE is informative but much richer information is available when PA and exercise intensity is monitored, not simply the total dose of PA undertaken. One of the fundamental shortcomings of any approach, again irrespective of the level of sophistication, is the integrity of the device. This includes the reliability of each instrument and whether the device has been calibrated to each individual for maximum benefit.

In summary, PA is a complex construct encompassing different dimensions, such as PAEE or MVPA; a range of contexts such as occupation, transportation, exercise, and daily activities; and different types of activity or exercise (177). Given the variety of applications for measures of PA, for example, in surveillance, 
epidemiology, clinical, and intervention research, it is highly unlikely that a single measure of reported PA would suffice, indeed be achievable. As mentioned in an earlier section, significant advances have been made with approaches that combine objective measures such as accelerometers, HR monitors, and geographic location sensors with self-report of context and purpose, sometimes reported in real time $(154,177)$.

Troiano (177) has provided sound advice regarding improvements to self-report approaches, including the suggestion that consideration of study or project requirement influence the choice of assessment instrument. Specifically, what aspect(s) of PA does one wish to measure, what are the characteristics of the target population, and will the data be used to describe groups or individuals? Secondly, Troiano (177) suggests that findings from self-report instruments should be addressed as "reported PA" in recognition that what has been reported may not "precisely and accurately reflect the behavior being sought."

\section{AUTHOR CONTRIBUTIONS}

All authors made substantial contributions to the conception and design of the paper. Andrew P. Hills drafted the review and Najat Mokhtar and Nuala M. Byrne revised it critically for content. All authors approved the final submission of the document and agree to be accountable for all aspects of the work.

\section{REFERENCES}

1. Caspersen CJ, Powell KE, Christenson GM. Physical activity, exercise, and physical fitness: definitions and distinctions for health-related research. Public Health Rep (1985) 100(2):126-31.

2. Ainsworth BE. How do I measure physical activity in my patients? Questionnaires and objective methods. Br J Sports Med (2009) 43(1):6-9. doi:10.1136/ bjsm.2008.052449

3. Dencker M, Andersen LB. Accelerometer-measured daily physical activity related to aerobic fitness in children and adolescents. J Sports Sci (2011) 29(9):887-95. doi:10.1080/02640414.2011.578148

4. Tudor-Locke C, Bassett DR Jr. How many steps/day are enough? Preliminary pedometer indices for public health. Sports Med (2004) 34(1):1-8. doi:10.2165/00007256-200434010-00001

5. Corder K, Brage S, Wareham NJ, Ekelund U. Comparison of PAEE from combined and separate heart rate and movement models in children. Med Sci Sports Exerc (2005) 37(10):1761-7. doi:10.1249/01.mss.0000176466.78408.cc

6. Kohl HW, Fulton JE, Caspersen CJ. Assessment of physical activity among children and adolescents: a review and synthesis. Prev Med (2000) 31:S54-76. doi:10.1006/pmed.1999.0542

7. Bailey RC, Olson J, Pepper SL, Porszasz J, Barstow TJ, Cooper DM. The level and tempo of children's physical activities: an observational study. Med Sci Sports Exerc (1995) 27(7):1033-41. doi:10.1249/00005768-199507000-00012

8. Lamonte MJ, Ainsworth BE. Quantifying energy expenditure and physical activity in the context of dose response. Med Sci Sports Exerc (2001) 33(6 Suppl):S370-8; discussion S419-20. doi:10.1097/00005768-200106001-00006

9. Bassett DR Jr. Validity and reliability issues in objective monitoring of physical activity. Res Q Exerc Sport (2000) 71(2 Suppl):S30-6.

10. DeLany JP, Lovejoy JC. Energy expenditure. Endocrinol Metab Clin North Am (1996) 25(4):831-46. doi:10.1016/S0889-8529(05)70357-1

11. Ainslie P, Reilly T, Westerterp K. Estimating human energy expenditure: a review of techniques with particular reference to doubly labelled water. Sports Med (2003) 33(9):683-98. doi:10.2165/00007256-200333090-00004

12. Dollman J, Okely AD, Hardy L, Timperio A, Salmon J, Hills AP. A hitchhiker's guide to assessing young people's physical activity: deciding what method to use. J Sci Med Sport (2009) 12(5):518-25. doi:10.1016/j.jsams.2008.09.007

13. Schutz Y, Weinsier RL, Hunter GR. Assessment of free-living physical activity in humans: an overview of currently available and proposed new measures. Obes Res (2001) 9(6):368-79. doi:10.1038/oby.2001.48
14. Westerterp KR. Assessment of physical activity: a critical appraisal. Eur J Appl Physiol (2009) 105(6):823-8. doi:10.1007/s00421-009-1000-2

15. Chen KY, Bassett DR Jr. The technology of accelerometry-based activity monitors: current and future. Med Sci Sports Exerc (2005) 37(11 Suppl):S490-500. doi:10.1249/01.mss.0000185571.49104.82

16. Howley ET. Type of activity: resistance, aerobic and leisure versus occupational physical activity. Med Sci Sports Exerc (2001) 33(6 Suppl):S364-9. doi:10.1097/00005768-200106001-00005 discussion S419-20,

17. Ainsworth BE, Haskell WL, Whitt MC, Irwin ML, Swartz AM, Strath SJ, et al. Compendium of physical activities: an update of activity codes and MET intensities. Med Sci Sports Exerc (2000) 32(9 Suppl):S498-504. doi:10.1097/ 00005768-200009001-00009

18. Byrne NM, Hills AP, Hunter GR, Weinsier RL, Schutz Y. Metabolic equivalent: one size does not fit all. J Appl Physiol (2005) 99(3):1112-9. doi:10.1152/ japplphysiol.00023.2004

19. Leenders NY, Sherman WM, Nagaraja HN, Kien CL. Evaluation of methods to assess physical activity in free-living conditions. Med Sci Sports Exerc (2001) 33(7):1233-40. doi:10.1097/00005768-200107000-00024

20. Racette SB, Schoeller DA, Kushner RF. Comparison of heart rate and physical activity recall with doubly labeled water in obese women. Med Sci Sports Exerc (1995) 27(1):126-33. doi:10.1249/00005768-199501000-00022

21. DeLany JP. Energy requirement methodology. 3rd ed. In: Coulston AM, Boushey CJ, Ferruzzi M, editors. Nutrition in the Prevention and Treatment of Disease. New York, NY: Academic Press (2013). p. 81-3.

22. Nelson KM, Weinsier RL, Long CL, Schutz Y. Prediction of resting energy expenditure from fat-free mass and fat mass. Am J Clin Nutr (1992) 56(5):848-56.

23. Speakman JR, Selman C. Physical activity and resting metabolic rate. Proc Nutr Soc (2003) 62(3):621-34. doi:10.1079/PNS2003282

24. Weinsier RL, Schutz Y, Bracco D. Reexamination of the relationship of resting metabolic rate to fat-free mass and to the metabolically active components of fat-free mass in humans. Am J Clin Nutr (1992) 55(4):790-4.

25. Kleiber M. Body size and metabolic rate. Physiol Rev (1947) 27(4):511-41.

26. Frisard MI, Broussard A, Davies SS, Roberts LJ II, Rood J, de Jonge L, et al. Aging, resting metabolic rate, and oxidative damage: results from the Louisiana Healthy Aging Study. J Gerontol A Biol Sci Med Sci (2007) 62(7):752-9. doi:10.1093/gerona/62.7.752

27. Keys A, Taylor HL, Grande F. Basal metabolism and age of adult man. Metabolism (1973) 22(4):579-87. doi:10.1016/0026-0495(73)90071-1

28. Luhrmann PM, Edelmann-Schafer B, Neuhauser-Berthold M. Changes in resting metabolic rate in an elderly German population: cross-sectional and longitudinal data. J Nutr Health Aging (2010) 14(3):232-6. doi:10.1007/s12603010-0055-4

29. Piers LS, Soares MJ, McCormack LM, O’Dea K. Is there evidence for an agerelated reduction in metabolic rate? J Appl Physiol (1998) 85(6):2196-204.

30. Arciero PJ, Goran MI, Poehlman ET. Resting metabolic rate is lower in women than in men. J Appl Physiol (1993) 75(6):2514-20.

31. DeLany JP, Bray GA, Harsha DW, Volaufova J. Energy expenditure in African American and white boys and girls in a 2-y follow-up of the Baton Rouge Children's Study. Am J Clin Nutr (2004) 79(2):268-73.

32. Leonard WR. Laboratory and field methods for measuring human energy expenditure. Am J Hum Biol (2012) 24(3):372-84. doi:10.1002/ajhb.22260

33. Lam YY, Redman LM, Smith SR, Bray GA, Greenway FL, Johannsen D, et al. Determinants of sedentary 24-h energy expenditure: equations for energy prescription and adjustment in a respiratory chamber. Am J Clin Nutr (2014) 99:834-42. doi:10.3945/ajcn.113.079566

34. de Jonge L, DeLany JP, Nguyen T, Howard J, Hadley EC, Redman LM, et al. Validation study of energy expenditure and intake during calorie restriction using doubly labeled water and changes in body composition. Am J Clin Nutr (2007) 85(1):73-9.

35. Jequier E, Schutz Y. Long-term measurements of energy expenditure in humans using a respiration chamber. Am J Clin Nutr (1983) 38(6):989-98.

36. Ravussin E, Lillioja S, Anderson TE, Christin L, Bogardus C. Determinants of 24-hour energy expenditure in man. Methods and results using a respiratory chamber. J Clin Invest (1986) 78(6):1568-78. doi:10.1172/JCI112749

37. Weir JB. New methods for calculating metabolic rate with special reference to protein metabolism. J Physiol (1949) 109(1-2):1-9.

38. Livesey G, Elia M. Estimation of energy expenditure, net carbohydrate utilization, and net fat oxidation and synthesis by indirect calorimetry: evaluation 
of errors with special reference to the detailed composition of fuels. Am J Clin Nutr (1988) 47(4):608-28.

39. Schoeller DA, van Santen E. Measurement of energy expenditure in humans by doubly labeled water method. J Appl Physiol (1982) 53(4):955-9.

40. International Atomic Energy Agency. Assessment of Body Composition and Total Energy Expenditure in Humans Using Stable Isotope Techniques. Vienna: International Atomic Energy Agency (2009).

41. Schoeller DA, Webb P. Five-day comparison of the doubly labeled water method with respiratory gas exchange. Am J Clin Nutr (1984) 40(1):153-8.

42. Westerterp KR, Plasqui G. Physical activity and human energy expenditure. Curr Opin Clin Nutr Metab Care (2004) 7(6):607-13. doi:10.1097/00075197200411000-00004

43. Wong WW, Roberts SB, Racette SB, Das SK, Redman LM, Rochon J, et al. The doubly labeled water method produces highly reproducible longitudinal results in nutrition studies. J Nutr (2014) 144(5):777-83. doi:10.3945/jn.113.187823

44. Schoeller DA. Measurement of energy expenditure in free-living humans by using doubly labeled water. J Nutr (1988) 118(11):1278-89.

45. Schoeller DA. Insights into energy balance from doubly labeled water. Int JObes (2008) 32(Suppl 7):S72-5. doi:10.1038/ijo.2008.241

46. Speakman JR, Thomson SC. Validation of the labeled bicarbonate technique for measurement of short-term energy expenditure in the mouse. $Z$ Ernahrungswiss (1997) 36(4):273-7. doi:10.1007/BF01617797

47. Speakman JR. The history and theory of the doubly labeled water technique. Am J Clin Nutr (1998) 68(4):932S-8S.

48. Frankenfield D, Roth-Yousey L, Compher C. Comparison of predictive equations for resting metabolic rate in healthy nonobese and obese adults: a systematic review. J Am Diet Assoc (2005) 105(5):775-89. doi:10.1016/j.jada.2005.02. 005

49. Frankenfield DC, Muth ER, Rowe WA. The Harris-Benedict studies of human basal metabolism: history and limitations. J Am Diet Assoc (1998) 98(4):439-45. doi:10.1016/S0002-8223(98)00100-X

50. Harris JA, Benedict FG. A biometric study of human basal metabolism. Proc Natl Acad Sci U S A (1918) 4(12):370-3. doi:10.1073/pnas.4.12.370

51. Black AE, Coward WA, Cole TJ, Prentice AM. Human energy expenditure in affluent societies: an analysis of 574 doubly-labelled water measurements. Eur J Clin Nutr (1996) 50(2):72-92.

52. Prentice AM, Black AE, Coward WA, Cole TJ. Energy expenditure in overweight and obese adults in affluent societies: an analysis of 319 doubly-labelled water measurements. Eur J Clin Nutr (1996) 50(2):93-7.

53. James WPT, Schofield EA, editors. Human Energy Requirements: A Manual for Planners and Nutritionists. Oxford: Oxford University Press (1990).

54. Black AE. Critical evaluation of energy intake using the Goldberg cut-off for energy intake:basal metabolic rate. A practical guide to its calculation, use and limitations. Int J Obes (2000) 24(9):1119-30. doi:10.1038/sj.ijo.0801376

55. Jette M, Sidney K, Blumchen G. Metabolic equivalents (METS) in exercise testing, exercise prescription, and evaluation of functional capacity. Clin Cardiol (1990) 13(8):555-65. doi:10.1002/clc.4960130809

56. Ainsworth BE, Haskell WL, Herrmann SD, Meckes N, Bassett DR Jr, TudorLocke C, et al. 2011 Compendium of physical activities: a second update of codes and MET values. Med Sci Sports Exerc (2011) 43(8):1575-81. doi:10.1249/MSS.0b013e31821ece12

57. Ainsworth BE, Haskell WL, Leon AS, Jacobs DR Jr, Montoye HJ, Sallis JF, et al. Compendium of physical activities: classification of energy costs of human physical activities. Med Sci Sports Exerc (1993) 25(1):71-80. doi:10. 1249/00005768-199301000-00011

58. Manson JE, Hu FB, Rich-Edwards JW, Colditz GA, Stampfer MJ, Willett WC, et al. A prospective study of walking as compared with vigorous exercise in the prevention of coronary heart disease in women. $N$ Engl J Med (1999) 341(9):650-8. doi:10.1056/NEJM199908263410904

59. Blair SN, Haskell WL, Ho P, Paffenbarger RS Jr, Vranizan KM, Farquhar JW, et al. Assessment of habitual physical activity by a seven-day recall in a community survey and controlled experiments. Am J Epidemiol (1985) 122(5): 794-804.

60. Bouchard C, Tremblay A, Leblanc C, Lortie G, Savard R, Theriault G. A method to assess energy expenditure in children and adults. Am J Clin Nutr (1983) 37(3):461-7.

61. Sallis JF, Buono MJ, Roby JJ, Micale FG, Nelson JA. Seven-day recall and other physical activity self-reports in children and adolescents. Med Sci Sports Exerc (1993) 25(1):99-108. doi:10.1249/00005768-199301000-00014
62. Wilms B, Ernst B, Thurnheer M, Weisser B, Schultes B. Correction factors for the calculation of metabolic equivalents (MET) in overweight to extremely obese subjects. Int J Obes (Lond) (2014):1-5. doi:10.1038/ijo.2014.22

63. Sirard JR, Pate RR. Physical activity assessment in children and adolescents. Sports Med (2001) 31(6):439-54. doi:10.2165/00007256-200131060-00004

64. Freedson PS, Miller K. Objective monitoring of physical activity using motion sensors and heart rate. Res Q Exerc Sport (2000) 71(2 Suppl):S21-9.

65. Livingstone MB. Heart-rate monitoring: the answer for assessing energy expenditure and physical activity in population studies? Br J Nutr (1997) 78(6):869-71. doi:10.1079/BJN19970205

66. Ceesay SM, Prentice AM, Day KC, Murgatroyd PR, Goldberg GR, Scott W, et al. The use of heart rate monitoring in the estimation of energy expenditure: a validation study using indirect whole-body calorimetry. Br J Nutr (1989) 61(2):175-86. doi:10.1079/BJN19890107

67. Leonard WR. Measuring human energy expenditure: what have we learned from the flex-heart rate method? Am J Hum Biol (2003) 15(4):479-89. doi:10.1002/ajhb.10187

68. Achten J, Jeukendrup AE. Heart rate monitoring: applications and limitations. Sports Med (2003) 33(7):517-38. doi:10.2165/00007256-200333070-00004

69. Li R, Deurenberg P, Hautvast JG. A critical evaluation of heart rate monitoring to assess energy expenditure in individuals. Am J Clin Nutr (1993) 58(5):602-7.

70. Luke A, Maki KC, Barkey N, Cooper R, McGee D. Simultaneous monitoring of heart rate and motion to assess energy expenditure. Med Sci Sports Exerc (1997) 29(1):144-8. doi:10.1097/00005768-199701000-00021

71. Stubbs RJ, Hughes DA, Johnstone AM, Whybrow S, Horgan GW, King N, et al. Rate and extent of compensatory changes in energy intake and expenditure in response to altered exercise and diet composition in humans. Am JPhysiol Regul Integr Comp Physiol (2004) 286(2):R350-8. doi:10.1152/ajpregu. 00196.2003

72. Eston RG, Rowlands AV, Ingledew DK. Validity of heart rate, pedometry, and accelerometry for predicting the energy cost of children's activities. JAppl Physiol (1998) 84(1):362-71.

73. Trost SG, Ward DS, Moorehead SM, Watson PD, Riner W, Burke JR. Validity of the Computer Science and Applications (CSA) activity monitor in children. Med Sci Sports Exerc (1998) 30(4):629-33. doi:10.1097/00005768-19980400000023

74. Ekelund U, Poortvliet E, Yngve A, Hurtig-Wennlov A, Nilsson A, Sjostrom M. Heart rate as an indicator of the intensity of physical activity in human adolescents. Eur J Appl Physiol (2001) 85(3-4):244-9. doi:10.1007/s004210100436

75. Livingstone MB, Coward WA, Prentice AM, Davies PS, Strain JJ, McKenna PG, et al. Daily energy expenditure in free-living children: comparison of heartrate monitoring with the doubly labeled water $(2 \mathrm{H} 2(18) \mathrm{O})$ method. Am JClin Nutr (1992) 56(2):343-52.

76. American College of Sports Medicine Position Stand. The recommended quantity and quality of exercise for developing and maintaining cardiorespiratory and muscular fitness, and flexibility in healthy adults. Med Sci Sports Exerc (1998) 30:975-91. doi:10.1097/00005768-199806000-00032

77. Le Masurier GC, Tudor-Locke C. Comparison of pedometer and accelerometer accuracy under controlled conditions. Med Sci Sports Exerc (2003) 35(5):867-71. doi:10.1249/01.MSS.0000064996.63632.10

78. Tudor-Locke C, Sisson SB, Collova T, Lee SM, Swan PD. Pedometer-determined step count guidelines for classifying walking intensity in a young ostensibly healthy population. Can J Appl Physiol (2005) 30(6):666-76. doi:10.1139/h05147

79. Melanson EL, Knoll JR, Bell ML, Donahoo WT, Hill JO, Nysse LJ, et al. Commercially available pedometers: considerations for accurate step counting. Prev Med (2004) 39(2):361-8. doi:10.1016/j.ypmed.2004.01.032

80. Schneider PL, Crouter S, Bassett DR. Pedometer measures of free-living physical activity: comparison of 13 models. Med Sci Sports Exerc (2004) 36(2):331-5. doi:10.1249/01.MSS.0000113486.60548.E9

81. Schneider PL, Crouter SE, Lukajic O, Bassett DR Jr. Accuracy and reliability of 10 pedometers for measuring steps over a $400-\mathrm{m}$ walk. Med Sci Sports Exerc (2003) 35(10):1779-84. doi:10.1097/00005768-200305001-01572

82. Tudor-Locke C, McClain JJ, Hart TL, Sisson SB, Washington TL. Expected values for pedometer-determined physical activity in youth. Res Q Exerc Sport (2009) 80(2):164-74. doi:10.1080/02701367.2009.10599550

83. Tudor-Locke C, Sisson SB, Lee SM, Craig CL, Plotnikoff RC, Bauman A. Evaluation of quality of commercial pedometers. Can J Public Health (2006) 97(Suppl 1):S10-5, S10-6. 
84. Abel MG, Peritore N, Shapiro R, Mullineaux DR, Rodriguez K, Hannon JC. A comprehensive evaluation of motion sensor step-counting error. Appl Physiol Nutr Metab (2011) 36(1):166-70. doi:10.1139/H10-095

85. Hendelman D, Miller K, Baggett C, Debold E, Freedson P. Validity of accelerometry for the assessment of moderate intensity physical activity in the field. Med Sci Sports Exerc (2000) 32(9 Suppl):S442-9. doi:10.1097/00005768200009001-00002

86. Le Masurier GC, Lee SM, Tudor-Locke C. Motion sensor accuracy under controlled and free-living conditions. Med Sci Sports Exerc (2004) 36(5):905-10. doi:10.1249/01.MSS.0000126777.50188.73

87. Abel MG, Hannon JC, Eisenman PA, Ransdell LB, Pett M, Williams DP. Waist circumference, pedometer placement, and step-counting accuracy in youth. Res Q Exerc Sport (2009) 80(3):434-44. doi:10.1080/02701367.2009. 10599581

88. Crouter SE, Schneider PL, Bassett DR Jr. Spring-levered versus piezo-electric pedometer accuracy in overweight and obese adults. Med Sci Sports Exerc (2005) 37(10):1673-9. doi:10.1249/01.mss.0000181677.36658.a8

89. Crouter SE, Churilla JR, Bassett DR Jr. Estimating energy expenditure using accelerometers. Eur J Appl Physiol (2006) 98(6):601-12. doi:10.1007/s00421006-0307-5

90. Crouter SE, Clowers KG, Bassett DR Jr. A novel method for using accelerometer data to predict energy expenditure. J Appl Physiol (2006) 100(4):1324-31. doi:10.1152/japplphysiol.00818.2005

91. Bassey EJ, Dallosso HM, Fentem PH, Irving JM, Patrick JM. Validation of a simple mechanical accelerometer (pedometer) for the estimation of walking activity. Eur J Appl Physiol Occup Physiol (1987) 56(3):323-30. doi:10.1007/ BF00690900

92. Tudor-Locke CE, Myers AM. Methodological considerations for researchers and practitioners using pedometers to measure physical (ambulatory) activity. Res Q Exerc Sport (2001) 72(1):1-12. doi:10.1080/02701367.2001.10608926

93. Ridgers ND, Fairclough S. Assessing free-living physical activity using accelerometry: practical issues for researchers and practitioners. Eur J Sport Sci (2011) 11(3):205-13. doi:10.1080/17461391.2010.501116

94. Trost SG. Objective measurement of physical activity in youth: current issues, future directions. Exerc Sport Sci Rev (2001) 29(1):32-6. doi:10.1097/ 00003677-200101000-00007

95. van Cauwenberghe E, Labarque V, Trost SG, de Bourdeaudhuij I, Cardon G. Calibration and comparison of accelerometer cut points in preschool children. Int J Pediatr Obes (2011) 6(2-2):e582-9. doi:10.3109/17477166.2010.526223

96. Oliver M, Schofield GM, Kolt GS, Schluter PJ. Pedometer accuracy in physical activity assessment of preschool children. J Sci Med Sport (2007) 10(5):303-10. doi:10.1016/j.jsams.2006.07.004

97. Van Cauwenberghe E, Jones RA, Hinkley T, Crawford D, Okely AD. Patterns of physical activity and sedentary behaviour in preschool children. Int J Behav Nutr Phys Act (2012) 9:138. doi:10.1186/1479-5868-9-138

98. Corder K, Brage S, Ekelund U. Accelerometers and pedometers: methodology and clinical application. Curr Opin Clin Nutr Metab Care (2007) 10(5):597-603. doi:10.1097/MCO.0b013e328285d883

99. de Vries SI, Bakker I, Hopman-Rock M, Hirasing RA, van Mechelen W. Clinimetric review of motion sensors in children and adolescents. J Clin Epidemiol (2006) 59(7):670-80. doi:10.1016/j.jclinepi.2005.11.020

100. Oliver M, Schofield GM, Kolt GS. Physical activity in preschoolers: understanding prevalence and measurement issues. Sports Med (2007) 37(12):1045-70. doi:10.2165/00007256-200737120-00004

101. Rowlands AV. Accelerometer assessment of physical activity in children: an update. Pediatr Exerc Sci (2007) 19(3):252-66.

102. Ward DS, Evenson KR, Vaughn A, Rodgers AB, Troiano RP. Accelerometer use in physical activity: best practices and research recommendations. Med Sci Sports Exerc (2005) 37(11 Suppl):S582-8. doi:10.1249/01.mss.0000185292.71933.91

103. Cliff DP, Reilly JJ, Okely AD. Methodological considerations in using accelerometers to assess habitual physical activity in children aged $0-5$ years. $J$ Sci Med Sport (2009) 12(5):557-67. doi:10.1016/j.jsams.2008.10.008

104. Pate RR, O’Neill JR, Mitchell J. Measurement of physical activity in preschool children. Med Sci Sports Exerc (2010) 42(3):508-12. doi:10.1249/ MSS.0b013e3181cea116

105. Westerterp KR. Physical activity assessment with accelerometers. Int J Obes (1999) 23(Suppl 3):S45-9. doi:10.1038/sj.ijo.0800883

106. Corder K, van Sluijs EM, Wright A, Whincup P, Wareham NJ, Ekelund U. Is it possible to assess free-living physical activity and energy expenditure in young people by self-report? Am J Clin Nutr (2009) 89(3):862-70. doi:10.3945/ajcn. 2008.26739

107. Van Cauwenberghe E, Gubbels J, De Bourdeaudhuij I, Cardon G. Feasibility and validity of accelerometer measurements to assess physical activity in toddlers. Int J Behav Nutr Phys Act (2011) 8:67. doi:10.1186/1479-58688-67

108. Reilly JJ, Penpraze V, Hislop J, Davies G, Grant S, Paton JY. Objective measurement of physical activity and sedentary behaviour: review with new data. Arch Dis Child (2008) 93(7):614-9. doi:10.1136/adc.2007.133272

109. Biddle SJ, Gorely T, Marshall SJ, Murdey I, Cameron N. Physical activity and sedentary behaviours in youth: issues and controversies. JR Soc Promot Health (2004) 124(1):29-33. doi:10.1177/146642400312400110

110. Reilly JJ, Coyle J, Kelly L, Burke G, Grant S, Paton JY. An objective method for measurement of sedentary behavior in 3- to 4-year olds. Obes Res (2003) 11(10):1155-8. doi:10.1038/oby.2003.158

111. Hardy LL, Hills AP, Timperio A, Cliff D, Lubans D, Morgan PJ, et al. A hitchhiker's guide to assessing sedentary behaviour among young people: deciding what method to use. J Sci Med Sport (2013) 16(1):28-35. doi:10.1016/j.jsams. 2012.05.010

112. Lubans DR, Hesketh K, Cliff DP, Barnett LM, Salmon J, Dollman J, et al. A systematic review of the validity and reliability of sedentary behaviour measures used with children and adolescents. Obes Rev (2011) 12(10):781-99. doi:10.1111/j.1467-789X.2011.00896.x

113. Bland JM, Altman DG. Statistical methods for assessing agreement between two methods of clinical measurement. Lancet (1986) 1(8476):307-10. doi:10. 1016/S0140-6736(86)90837-8

114. Sallis JF. Self-report measures of children's physical activity. J Sch Health (1991) 61(5):215-9. doi:10.1111/j.1746-1561.1991.tb06017.x

115. Andersen LB, Harro M, Sardinha LB, Froberg K, Ekelund U, Brage S, et al. Physical activity and clustered cardiovascular risk in children: a cross-sectional study (The European Youth Heart Study). Lancet (2006) 368(9532):299-304. doi:10.1016/S0140-6736(06)69554-8

116. Ness AR, Leary SD, Mattocks C, Blair SN, Reilly JJ, Wells J, et al. Objectively measured physical activity and fat mass in a large cohort of children. PLoS Med (2007) 4(3):e97. doi:10.1371/journal.pmed.0040097

117. Wareham NJ, van Sluijs EM, Ekelund U. Physical activity and obesity prevention: a review of the current evidence. Proc Nutr Soc (2005) 64(2):229-47. doi:10.1079/PNS2005460

118. Riddoch CJ, Bo Andersen L, Wedderkopp N, Harro M, Klasson-Heggebo L, Sardinha LB, et al. Physical activity levels and patterns of 9- and 15-yr-old European children. Med Sci Sports Exerc (2004) 36(1):86-92. doi:10.1249/01. MSS.0000106174.43932.92

119. Bouten CV, Verboeket-van de Venne WP, Westerterp KR, Verduin M, Janssen JD. Daily physical activity assessment: comparison between movement registration and doubly labeled water. J Appl Physiol (1996) 81(2):1019-26.

120. Plasqui G, Westerterp KR. Physical activity assessment with accelerometers: an evaluation against doubly labeled water. Obesity (2007) 15(10):2371-9. doi:10.1038/oby.2007.281

121. Bouten CV, Koekkoek KT, Verduin M, Kodde R, Janssen JD. A triaxial accelerometer and portable data processing unit for the assessment of daily physical activity. IEEE Trans Biomed Eng (1997) 44(3):136-47. doi:10.1109/10. 554760

122. Bouten CV, Sauren AA, Verduin M, Janssen JD. Effects of placement and orientation of body-fixed accelerometers on the assessment of energy expenditure during walking. Med Biol Eng Comput (1997) 35(1):50-6. doi:10.1007/ BF02510392

123. Brage S, Wedderkopp N, Franks PW, Andersen LB, Froberg K. Reexamination of validity and reliability of the CSA monitor in walking and running Med Sci Sports Exerc (2003) 35(8):1447-54. doi:10.1097/00005768200305001-01573

124. Howe CA, Staudenmayer JW, Freedson PS. Accelerometer prediction of energy expenditure: vector magnitude versus vertical axis. Med Sci Sports Exerc (2009) 41(12):2199-206. doi:10.1249/MSS.0b013e3181aa3a0e

125. Maddison R, Jiang Y, Hoorn SV, Mhurchu CN, Lawes CM, Rodgers A, et al. Estimating energy expenditure with the RT3 triaxial accelerometer. Res Q Exerc Sport (2009) 80(2):249-56. doi:10.1080/02701367.2009.10599559

126. Plasqui G, Westerterp KR. Accelerometry and heart rate as a measure of physical fitness: proof of concept. Med Sci Sports Exerc (2005) 37(5):872-6. doi:10.1249/01.MSS.0000161805.61893.C0 
127. Freedson PS, Melanson E, Sirard J. Calibration of the Computer Science and Applications, Inc. accelerometer. Med Sci Sports Exerc (1998) 30(5):777-81. doi:10.1097/00005768-199805000-00021

128. Rowlands AV, Thomas PW, Eston RG, Topping R. Validation of the RT3 triaxial accelerometer for the assessment of physical activity. Med Sci Sports Exerc (2004) 36(3):518-24. doi:10.1249/01.MSS.0000117158.14542.E7

129. Swartz AM, Strath SJ, Bassett DR Jr, O’Brien WL, King GA, Ainsworth BE. Estimation of energy expenditure using CSA accelerometers at hip and wrist sites. Med Sci Sports Exerc (2000) 32(9 Suppl):S450-6. doi:10.1097/00005768200009001-00003

130. Dencker M, Andersen LB. Health-related aspects of objectively measured daily physical activity in children. Clin Physiol Funct Imaging (2008) 28(3):133-44. doi:10.1111/j.1475-097X.2008.00788.x

131. Puyau MR, Adolph AL, Vohra FA, Butte NF. Validation and calibration of physical activity monitors in children. Obes Res (2002) 10(3):150-7. doi:10.1038/ oby. 2002.24

132. Sirard JR, Riner WF Jr, McIver KL, Pate RR. Physical activity and active commuting to elementary school. Med Sci Sports Exerc (2005) 37(12):2062-9. doi:10.1249/01.mss.0000179102.17183.6b

133. Gutin B, Yin Z, Humphries MC, Barbeau P. Relations of moderate and vigorous physical activity to fitness and fatness in adolescents. Am J Clin Nutr (2005) 81(4):746-50.

134. Kolle E, Steene-Johannessen J, Andersen LB, Anderssen SA. Objectively assessed physical activity and aerobic fitness in a population-based sample of Norwegian 9- and 15-year-olds. Scand J Med Sci Sports (2010) 20(1):e41-7. doi:10.1111/j.1600-0838.2009.00892.x

135. Kristensen PL, Moeller NC, Korsholm L, Kolle E, Wedderkopp N, Froberg K, et al. The association between aerobic fitness and physical activity in children and adolescents: the European youth heart study. Eur J Appl Physiol (2010) 110 (2):267-75. doi:10.1007/s00421-010-1491-x

136. Dencker M, Bugge A, Hermansen B, Andersen LB. Objectively measured daily physical activity related to aerobic fitness in young children. J Sports Sci (2010) 28(2):139-45. doi:10.1080/02640410903460726

137. Treuth MS, Schmitz K, Catellier DJ, McMurray RG, Murray DM, Almeida MJ, et al. Defining accelerometer thresholds for activity intensities in adolescent girls. Med Sci Sports Exerc (2004) 36(7):1259-66.

138. Olds T, Ferrar KE, Gomersall SR, Maher C, Walters JL. The elasticity of time: associations between physical activity and use of time in adolescents. Health Educ Behav (2012) 39(6):732-6. doi:10.1177/1090198111429822

139. Troiano RP, Berrigan D, Dodd KW, Masse LC, Tilert T, McDowell M. Physical activity in the United States measured by accelerometer. Med Sci Sports Exerc (2008) 40(1):181-8. doi:10.1249/mss.0b013e31815a51b3

140. Welk GJ, Schaben JA, Morrow JR Jr. Reliability of accelerometry-based activity monitors: a generalizability study. Med Sci Sports Exerc (2004) 36(9):1637-45.

141. Brage S, Brage N, Franks PW, Ekelund U, Wong MY, Andersen LB, et al. Branched equation modeling of simultaneous accelerometry and heart rate monitoring improves estimate of directly measured physical activity energy expenditure. J Appl Physiol (1985) (2004) 96(1):343-51. doi:10.1152/ japplphysiol.00703.2003

142. Powell SM, Jones DI, Rowlands AV. Technical variability of the RT3 accelerometer. Med Sci Sports Exerc (2003) 35(10):1773-8. doi:10.1249/01. MSS.0000089341.68754.BA

143. Heil DP, Brage S, Rothney MP. Modeling physical activity outcomes from wearable monitors. Med Sci Sports Exerc (2012) 44(1S):S50-60. doi:10.1249/MSS 0b013e3182399dcc

144. Mannini A, Intille SS, Rosenberger M, Sabatini AM, Haskell W. Activity recognition using a single accelerometer placed at the wrist or ankle. Med Sci Sports Exerc (2013) 45(11):2193-203. doi:10.1249/MSS.0b013e31829736d6

145. De Vries SI, Van Hirtum HW, Bakker I, Hopman-Rock M, Hirasing RA, Van Mechelen W. Validity and reproducibility of motion sensors in youth: a systematic update. Med Sci Sports Exerc (2009) 41(4):818-27. doi:10.1249/MSS. 0b013e31818e5819

146. Trost SG, McIver KL, Pate RR. Conducting accelerometer-based activity assessments in field-based research. Med Sci Sports Exerc (2005) 37(11 Suppl):S531-43. doi:10.1249/01.mss.0000185657.86065.98

147. Van Cauwenberghe E, Wooller L, Mackay L, Cardon G, Oliver M. Comparison of actical and activPAL measures of sedentary behaviour in preschool children. J Sci Med Sport (2012) 15(6):526-31. doi:10.1016/j.jsams.2012.03.014
148. Pate RR, Almeida MJ, McIver KL, Pfeiffer KA, Dowda M. Validation and calibration of an accelerometer in preschool children. Obesity (2006) 14(11):2000-6. doi:10.1038/oby.2006.234

149. Pfeiffer KA, Dowda M, McIver KL, Pate RR. Factors related to objectively measured physical activity in preschool children. Pediatr Exerc Sci (2009) 21(2):196-208.

150. Haskell WL, Yee MC, Evans A, Irby PJ. Simultaneous measurement of heart rate and body motion to quantitate physical activity. Med Sci Sports Exerc (1993) 25(1):109-15. doi:10.1249/00005768-199301000-00015

151. Livingstone MB, Robson PJ, Totton M. Energy expenditure by heart rate in children: an evaluation of calibration techniques. Med Sci Sports Exerc (2000) 32(8):1513-9. doi:10.1097/00005768-200008000-00022

152. Hiilloskorpi HK, Pasanen ME, Fogelholm MG, Laukkanen RM, Manttari AT. Use of heart rate to predict energy expenditure from low to high activity levels. Int J Sports Med (2003) 24(5):332-6. doi:10.1055/s-2003-40701

153. Brage S, Brage N, Franks PW, Ekelund U, Wareham NJ. Reliability and validity of the combined heart rate and movement sensor actiheart. Eur J Clin Nutr (2005) 59(4):561-70. doi:10.1038/sj.ejcn.1602118

154. Dunton GF, Dzubur E, Kawabata K, Yanez B, Bo B, Intille S. Development of a smartphone application to measure physical activity using sensor-assisted self-report. Front Public Health (2014) 2:12. doi:10.3389/fpubh.2014.00012

155. Hurvitz PM, Moudon AV, Kang B, Saelens BE, Duncan GE. Emerging technologies for assessing physical activity behaviors in space and time. Front Public Health (2014) 2:2. doi:10.3389/fpubh.2014.00002

156. Casiraghi F, Lertwattanarak R, Luzi L, Chavez AO, Davalli AM, Naegelin T, et al. Energy expenditure evaluation in humans and non-human primates by SenseWear Armband. Validation of energy expenditure evaluation by SenseWear Armband by direct comparisoin with indirect calorimetry. PLoS One (2013) 8(9):e73651. doi:10.1371/journal.pone.0073651

157. Calabro MA, Stewart JM, Welk GJ. Validation of pattern-recognition monitors in children using doubly labelled water. Med Sci Sports Exerc (2013) 45(7):1313-22. doi:10.1249/MSS.0b013e31828579c3

158. Slinde F, Bertz F, Winkvist A, Ellegard L, Olausson H, Brekke HK. Energy expenditure by multisensor armband in overweight and obese lactating women validated by doubly labeled water. Obesity (2013) 21:2231-5. doi:10.1002/oby. 20363

159. Whybrow S, Ritz P, Horgan GW, Stubbs RJ. An evaluation of the IDEEA activity monitor for estimating energy expenditure. Br J Nutr (2013) 109(1):173-83. doi:10.1017/S0007114512000645

160. Zhang K, Pi-Sunyer FX, Boozer CN. Improving energy expenditure estimation for physical activity. Med Sci Sports Exerc (2004) 36(5):883-9. doi:10.1249/01. MSS.0000126585.40962.22

161. Zhang K, Werner P, Sun M, Pi-Sunyer FX, Boozer CN. Measurement of human daily physical activity. Obes Res (2003) 11(1):33-40. doi:10.1038/oby. 2003.7

162. Maffiuletti NA, Gorelick M, Kramers-de Quervain I, Bizzini M, Munzinger JP, Tomasetti S, et al. Concurrent validity and intrasession reliability of the IDEEA accelerometry system for the quantification of spatiotemporal gait parameters. Gait Posture (2008) 27(1):160-3. doi:10.1016/j.gaitpost.2007.01.003

163. Welk GJ, McClain JJ, Eisenmann JC, Wickel EE. Field validation of the MTI actigraph and bodymedia armband monitor using the IDEEA monitor. Obesity (2007) 15(4):918-28. doi:10.1038/oby.2007.624

164. Larsen TM, Dalskov S, van Baak M, Jebb S, Kafatos A, Pfeiffer A, et al. The diet, obesity and genes (diogenes) dietary study in eight European countries - a comprehensive design for long-term intervention. Obes Rev (2010) 11(1):76-91. doi:10.1111/j.1467-789X.2009.00603.x

165. Gorelick ML, Bizzini M, Maffiuletti NA, Munzinger JP, Munzinger U. Test-retest reliability of the IDEEA system in the quantification of step parameters during walking and stair climbing. Clin Physiol Funct Imaging (2009) 29(4):271-6. doi:10.1111/j.1475-097X.2009.00864.x

166. Ermes M, Parkka J, Mantyjarvi J, Korhonen I. Detection of daily activities and sports with wearable sensors in controlled and uncontrolled conditions. IEEE Trans Inf Technol Biomed (2008) 12(1):20-6. doi:10.1109/TITB.2007. 899496

167. Karantonis DM, Narayanan MR, Mathie M, Lovell NH, Celler BG. Implementation of a real-time human movement classifier using a triaxial accelerometer for ambulatory monitoring. IEEE Trans Inf Technol Biomed (2006) 10(1):156-67. doi:10.1109/TITB.2005.856864 
168. Bonomi AG, Goris AH, Yin B, Westerterp KR. Detection of type, duration, and intensity of physical activity using an accelerometer. Med Sci Sports Exerc (2009) 41(9):1770-7. doi:10.1249/MSS.0b013e3181a24536

169. Bonomi AG, Plasqui G, Goris AH, Westerterp KR. Improving assessment of daily energy expenditure by identifying types of physical activity with a single accelerometer. J Appl Physiol (2009) 107(3):655-61. doi:10.1152/japplphysiol. 00150.2009

170. Lyden K, Keadle SK, Staudenmayer J, Freedson PS. A method to estimate freeliving active and sedentary behavior from an accelerometer. Med Sci Sports Exerc (2014) 46(2):386-97. doi:10.1249/MSS.0b013e3182a42a2d

171. Dannecker KL, Sazonova NA, Melanson EL, Sazonov ES, Browning RC. A comparison of energy expenditure estimation of several physical activity monitors. Med Sci Sports Exerc (2013) 45(11):2105-12. doi:10.1249/MSS. $0 \mathrm{~b} 013 \mathrm{e} 318299 \mathrm{~d} 2 \mathrm{eb}$

172. Adam Noah J, Spierer DK, Gu J, Bronner S. Comparison of steps and energy expenditure assessment in adults of Fitbit Tracker and Ultra to the Actical and indirect calorimetry. J Med Eng Technol (2013) 37(7):456-62. doi:10.3109/03091902.2013.831135

173. Shephard RJ. Limits to the measurement of habitual physical activity by questionnaires. Br J Sports Med (2003) 37(3):197-206. doi:10.1136/bjsm.37.3.197

174. Van Remoortel H, Giavedoni S, Raste Y, Burtin C, Louvaris Z, Gimeno-Santos $\mathrm{E}$, et al. Validity of activity monitors in health and chronic disease: a systematic review. Int J Behav Nutr Phys Act (2012) 9:84. doi:10.1186/1479-5868-9-84

175. Van Remoortel H, Raste Y, Louvaris Z, Giavedoni S, Burtin C, Langer D, et al. Validity of six activity monitors in chronic obstructive pulmonary disease: a comparison with indirect calorimetry. PLoS One (2012) 7(6):e39198. doi:10.1371/journal.pone.0039198

176. Nielsen SB, Montgomery C, Kelly LA, Jackson DM, Reilly JJ. Energy intake variability in free-living young children. Arch Dis Child (2008) 93(11):971-3. doi:10.1136/adc.2007.134486

177. Troiano RP. Can there be a single best measure of reported physical activity? Am J Clin Nutr (2009) 89(3):736-7. doi:10.3945/ajcn.2008.27461

178. Bassett DR Jr, Cureton AL, Ainsworth BE. Measurement of daily walking distance-questionnaire versus pedometer. Med Sci Sports Exerc (2000) 32(5):1018-23. doi:10.1097/00005768-200005000-00021

179. Levine JA. Non-exercise activity thermogenesis. Proc Nutr Soc (2003) 62(3):667-79. doi:10.1079/PNS2003281

180. Spadano JL, Must A, Bandini LG, Dallal GE, Dietz WH. Energy cost of physical activities in 12-y-old girls: MET values and the influence of body weight. Int J Obes (2003) 27(12):1528-33. doi:10.1038/sj.ijo.0802440

181. Harrell JS, McMurray RG, Baggett CD, Pennell ML, Pearce PF, Bangdiwala SI. Energy costs of physical activities in children and adolescents. Med Sci Sports Exerc (2005) 37(2):329-36. doi:10.1249/01.MSS.0000153115.33762.3F

182. Ridley K, Ainsworth BE, Olds TS. Development of a compendium of energy expenditures for youth. Int J Behav Nutr Phys Act (2008) 5:45. doi:10.1186/ 1479-5868-5-45

183. Ellery CV, Weiler HA, Hazell TJ. Physical activity assessment tools for use in overweight and obese children. Int J Obes (2014) 38:1-10. doi:10.1038/ ijo.2013.125

184. Corder K, Ekelund U, Steele RM, Wareham NJ, Brage S. Assessment of physical activity in youth. J Appl Physiol (2008) 105(3):977-87. doi:10.1152/ japplphysiol.00094.2008

185. Arvidsson D, Slinde F, Hulthen L. Physical activity questionnaire for adolescents validated against doubly labelled water. Eur J Clin Nutr (2005) 59(3):376-83. doi:10.1038/sj.ejcn.1602084
186. Slinde F, Arvidsson D, Sjoberg A, Rossander-Hulthen L. Minnesota leisure time activity questionnaire and doubly labeled water in adolescents. Med Sci Sports Exerc (2003) 35(11):1923-8. doi:10.1249/01.MSS.0000093608.95629.85

187. Janz KF, Lutuchy EM, Wenthe P, Levy SM. Measuring activity in children and adolescents using self-report: PAQ-C and PAQ-A. Med Sci Sports Exerc (2008) 40(4):767-72. doi:10.1249/MSS.0b013e3181620ed1

188. Philippaerts RM, Matton L, Wijndaele K, Balduck AL, De Bourdeaudhuij I, Lefevre J. Validity of a physical activity computer questionnaire in 12- to 18year-old boys and girls. Int J Sports Med (2006) 27(2):131-6. doi:10.1055/s2005-837619

189. Corder K, Brage S, Mattocks C, Ness A, Riddoch C, Wareham NJ, et al. Comparison of two methods to assess PAEE during six activities in children. Med Sci Sports Exerc (2007) 39(12):2180-8. doi:10.1249/mss. 0b013e318150dff8

190. Ekelund U, Sjostrom M, Yngve A, Poortvliet E, Nilsson A, Froberg K, et al. Physical activity assessed by activity monitor and doubly labeled water in children. Med Sci Sports Exerc (2001) 33(2):275-81. doi:10.1097/00005768-20010200000017

191. Patterson P. Reliability, validity, and methodological response to the assessment of physical activity via self-report. Res Q Exerc Sport (2000) 71(2 Suppl):S15-20.

192. Neilson HK, Robson PJ, Friedenreich CM, Csizmadi I. Estimating activity energy expenditure: how valid are physical activity questionnaires? Am J Clin Nutr (2008) 87(2):279-91.

193. Ridley K, Olds TS, Hill A. The multimedia activity recall for children and adolescents (MARCA): development and evaluation. Int J Behav Nutr Phys Act (2006) 3:10. doi:10.1186/1479-5868-3-10

194. Gomersall SR, Olds TS, Ridley K. Development and evaluation of an adult useof-time instrument with an energy expenditure focus. J Sci Med Sport (2011) 14(2):143-8. doi:10.1016/j.jsams.2010.08.006

195. Foley L, Maddison R, Olds T, Ridley K. Self-report use-of-time tools for the assessment of physical activity and sedentary behaviour in young people: systematic review. Obes Rev (2012) 13(8):711-22. doi:10.1111/j.1467-789X.2012. 00993.x

196. Welk GJ, Kim Y, Stanfill B, Osthus DA, Calabro AM, Nusser SM, et al. Validity of 24-h physical activity recall: physical activity measurement survey. Med Sci Sports Exerc (2014). doi:10.1249/MSS.0000000000000314

Conflict of Interest Statement: The authors declare that the research was conducted in the absence of any commercial or financial relationships that could be construed as a potential conflict of interest.

Received: 24 April 2014; paper pending published: 12 May 2014; accepted: 27 May 2014; published online: 16 June 2014.

Citation: Hills AP, Mokhtar N and Byrne NM (2014) Assessment of physical activity and energy expenditure: an overview of objective measures. Front. Nutr. 1:5. doi: 10.3389/fnut.2014.00005

This article was submitted to Nutrition Methodology, a section of the journal Frontiers in Nutrition.

Copyright (C) 2014 Hills, Mokhtar and Byrne. This is an open-access article distributed under the terms of the Creative Commons Attribution License (CC BY). The use, distribution or reproduction in other forums is permitted, provided the original author(s) or licensor are credited and that the original publication in this journal is cited, in accordance with accepted academic practice. No use, distribution or reproduction is permitted which does not comply with these terms. 